\title{
Nano-Tera.ch
}

\section{Engineering Complex Systems}

for Health, Security and the Environment

Giovanni De Micheli
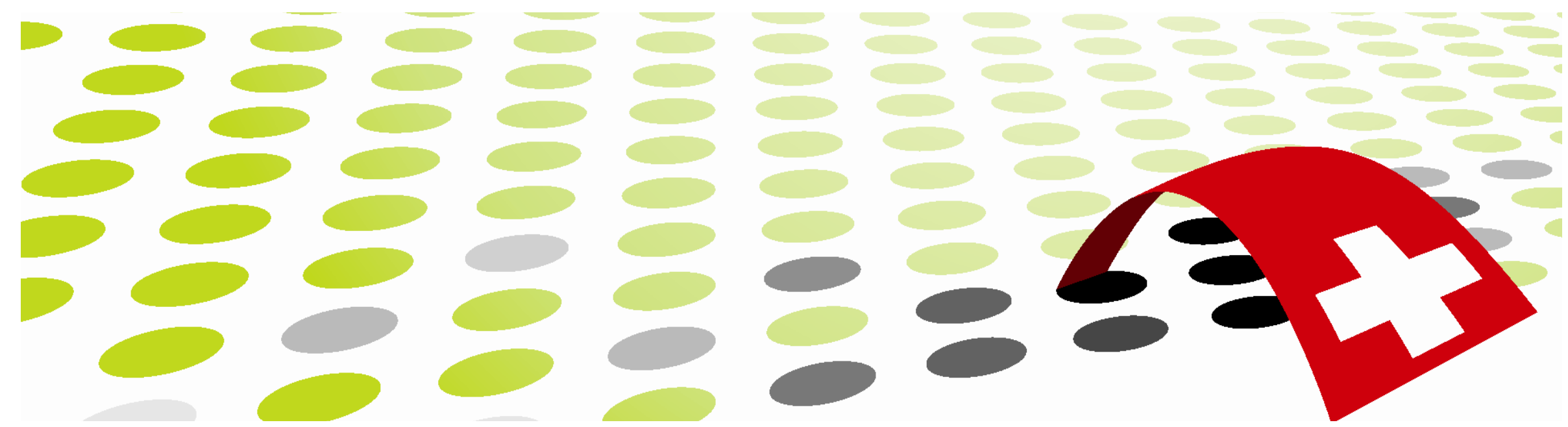


\section{Emerging societal and economic issues}

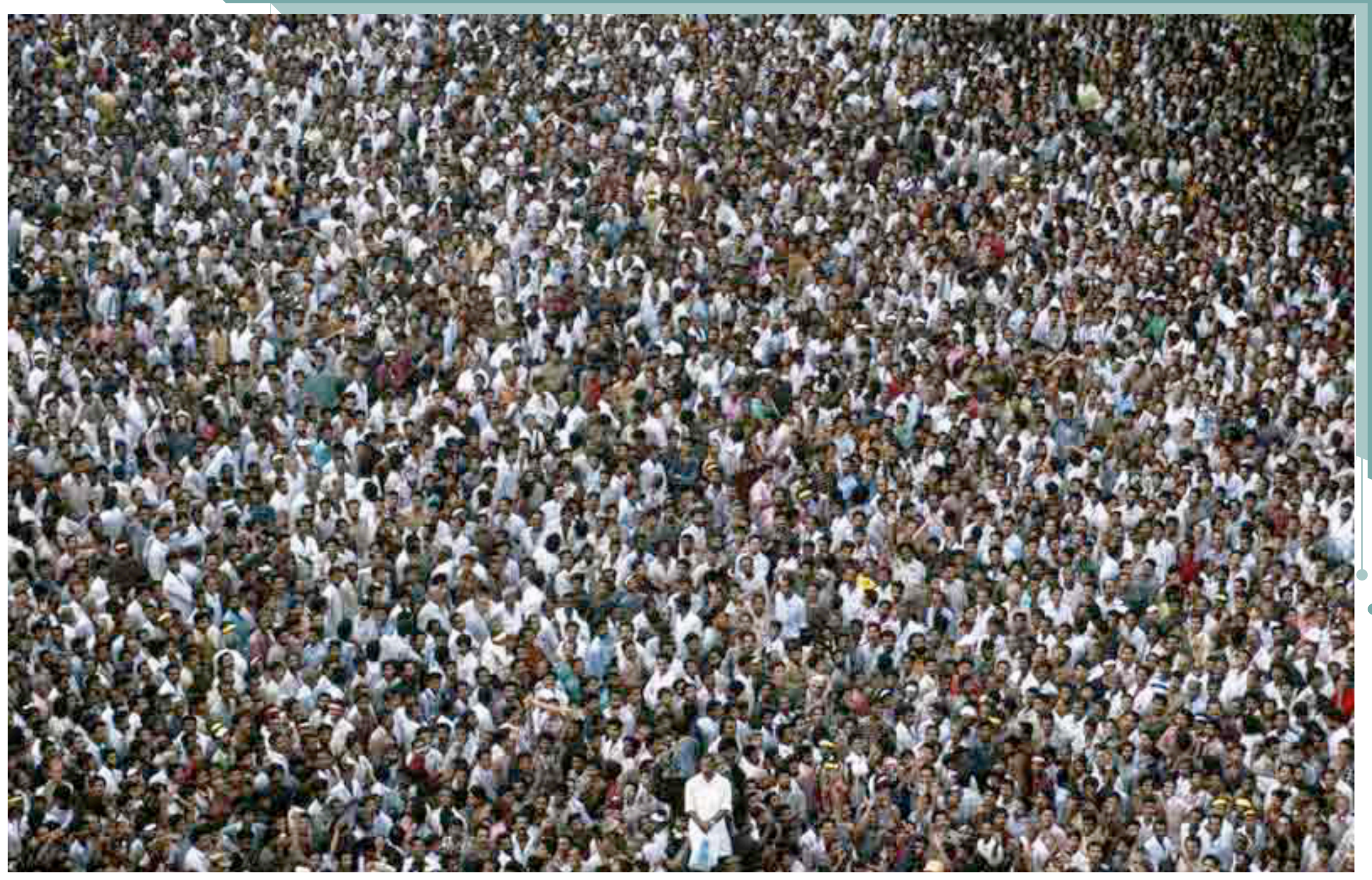




\section{The technology}

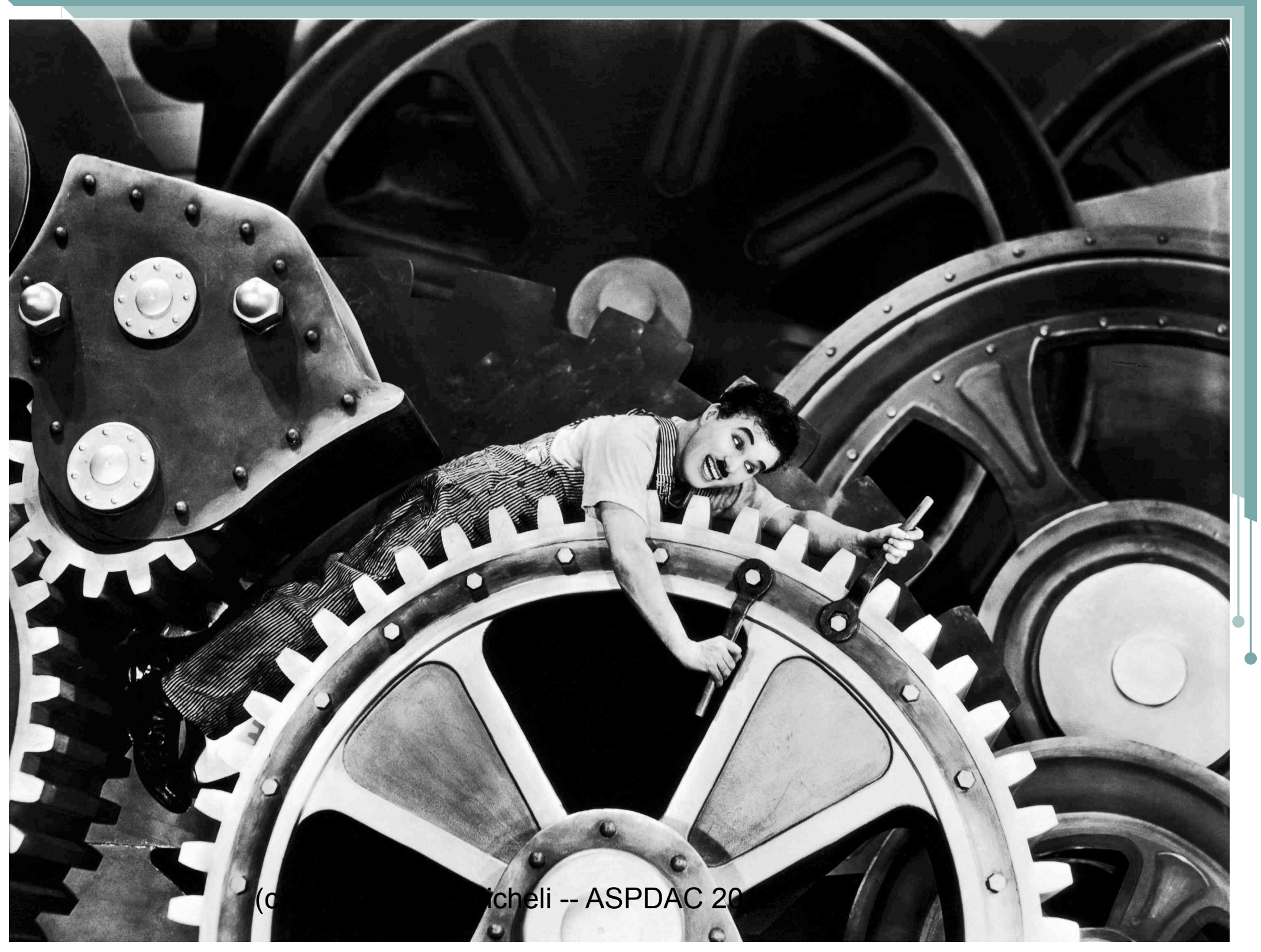




\section{Nano-Tera.ch}

- Health:

- High-throughput biology, real-time medical monitoring

- Environmental monitoring:

- Weather, pollution, seismic analysis

- Security:

- Cryptography, secure communication

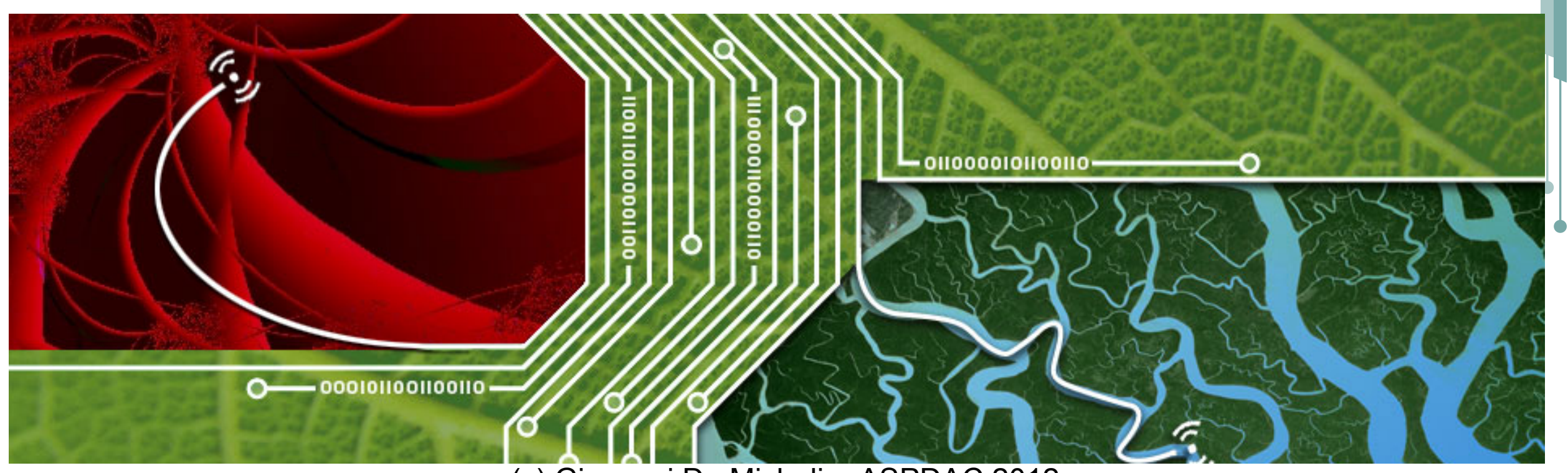

(c) Giovanni De Micheli -- ASPDAC 2012 


\section{Mission}

Research, Design \& Engineering of complex tera-scale systems using nano-scale devices and technologies

Foster research and crossbreeding of hw/sw technologies

Convergence of technologies: fertile ground for innovation

- Develop new markets

- Improve living standards

- Better the quality of health, security \& environment systems

- Foster a vision of engineering with social objectives

- Promote related educationl programs

\section{nano-tera.ch}




\section{Nano-Tera.ch: key figures}

- 59 Projects (19 RTD - 15 NTF - 19 ED - 6 SSSTC)

- 37 Research institutions (involved with PIs or CoPIs)

- 150 Research groups

- 27 Industrial partners

- 700 Researchers

- 120 Doctoral theses supported

- > 300 Papers published (2010-2011)

- Total Nano-Tera.ch funding support (2008-2011):

- 60 M CHF in cash (from Swiss Confederation)

- 61.8 M CHF in matching money

- Total funding support for 2012:

- 15 M CHF in cash 15 M CHF in matching support

- Support for 2013-2016 is being negotiated 


\section{RTD projects}

- Research, Technology and Development projects

- Multi-discipline projects

- Multi-institution projects

- Research on fundamental principles

- Applications toward technology demonstrators

- Selected and monitored through the Swiss National Science Foundation

- Budgets around 1MCHF/year (in cash)

- 19 projects currently supported 


\section{RTD Projects by themes}

19 RTD projects 3-4 years

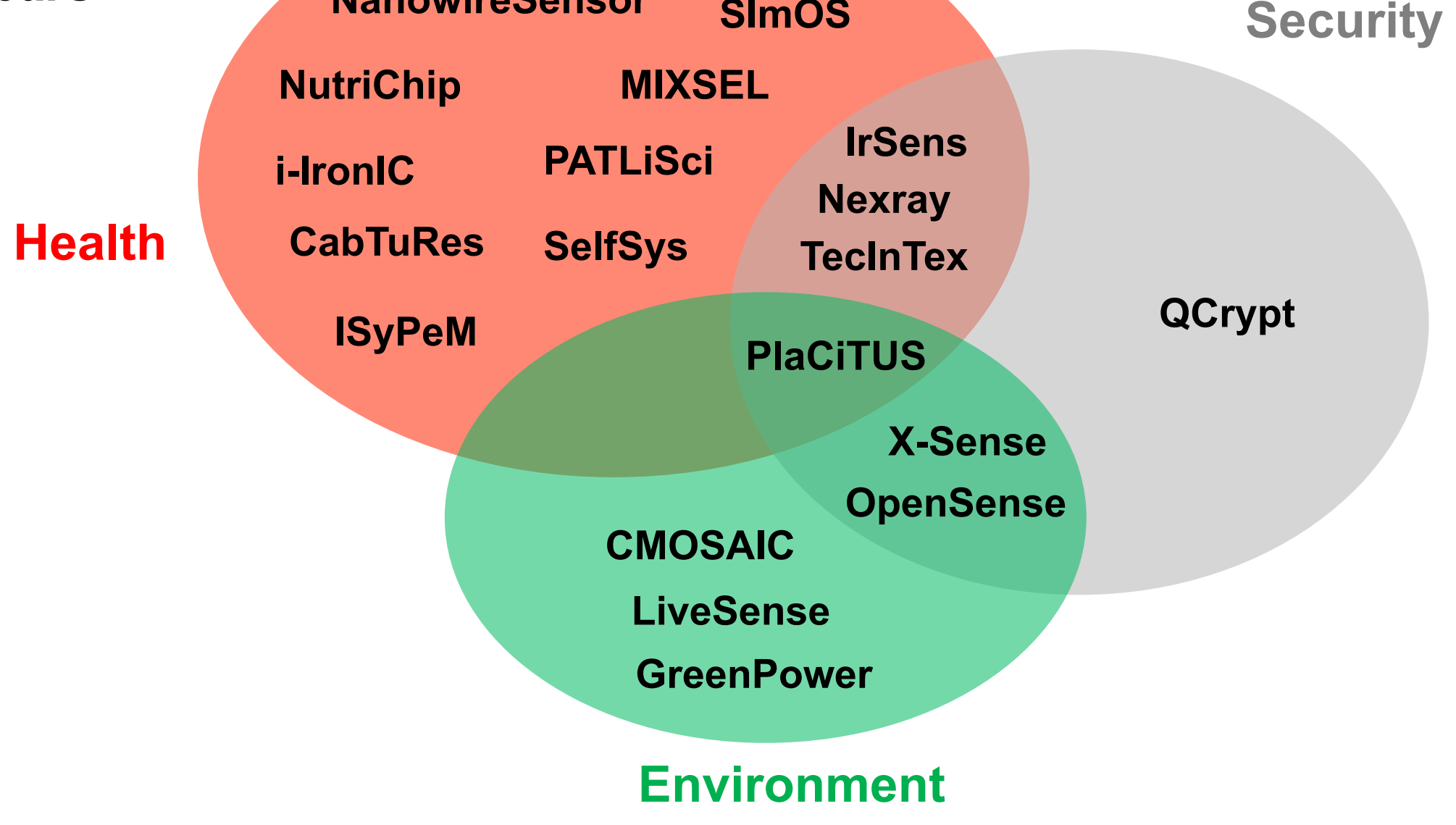




\section{Consortium institutions}

\section{Leading House}

EPFL Swiss Federal Institute of Technology Lausanne

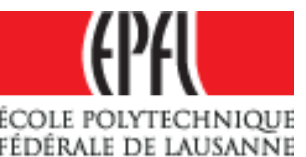

\section{Consortium}

CSEM Swiss Center for Electronics and Microtechnology

EPFL Swiss Federal Institute of Technology Lausanne

ETHZ Swiss Federal Institute of Technology Zurich

UniBas University of Basel

UniGE University of Geneva

UniNE University of Neuchâtel

USI University of Lugano

\section{csem}

\section{EH}

Eidgenössische Technische Hochschule Zürich Swiss Federal Institute of Technology Zurich

\section{$(P+1$}

ECOLE POLYTECHNIOUE

ÉCOLE POLYTECHNIQUY

EÉDERALE DE LAUSANN

UNIVERSITÉ

DE GENĖVE

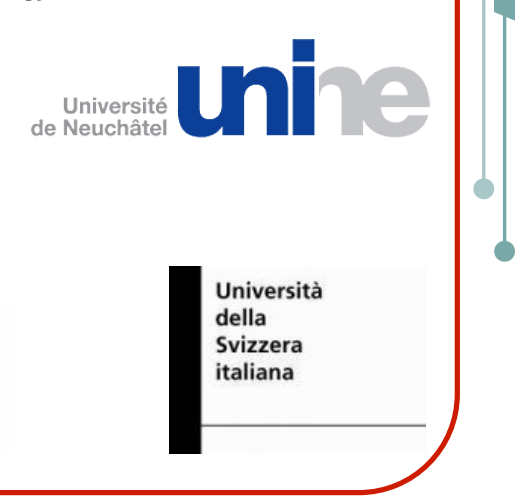

(c) Giovanni De Micheli -- ASPDAC 2012 


\section{7 participating institutions}
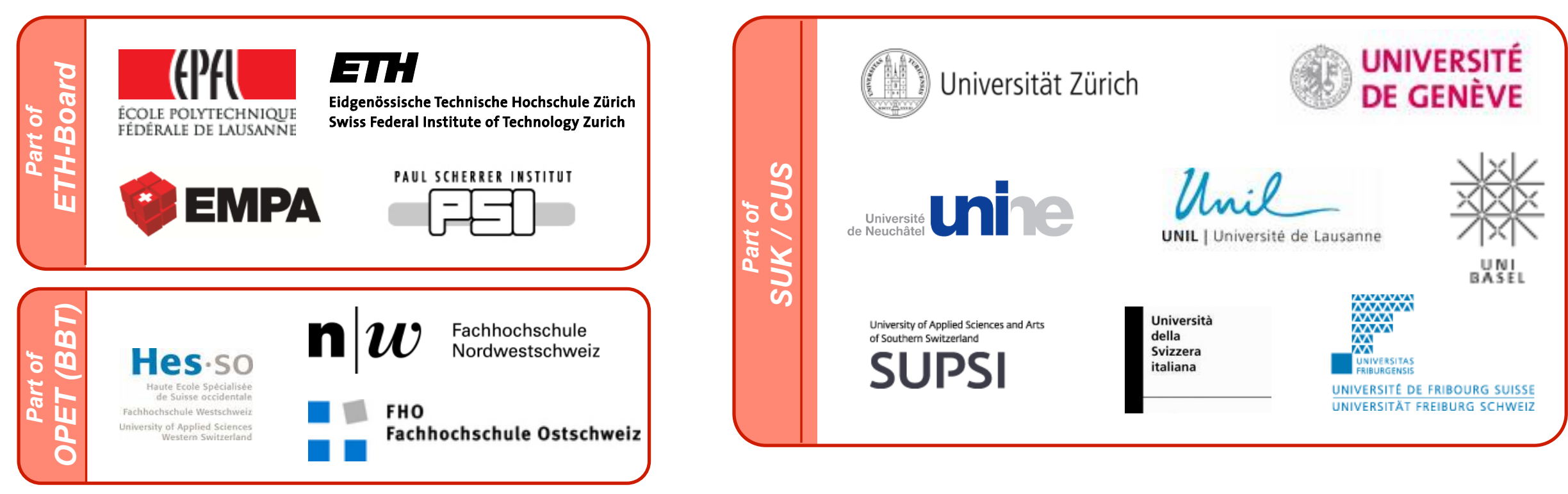

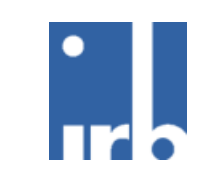

veare

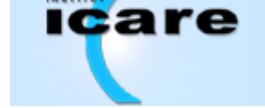

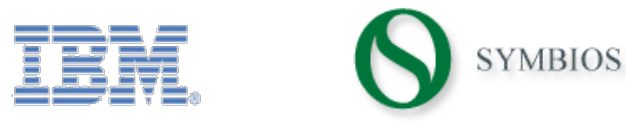

csem

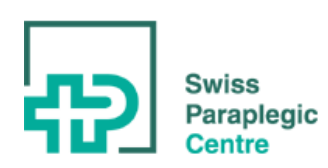

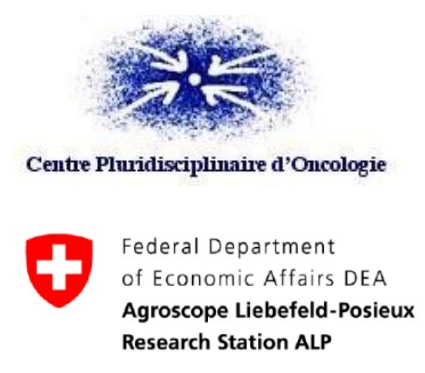

Agroscope Liebefeld-Posieux

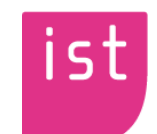

UniversitätsSpital Zürich

4

Schweizerische Eidgenossenschat
Confedération suisse Confederazione Svizzer
Confederaziun swiza

Swiss Confederation

Federal Office for the Environment FOEN 


\section{Distribution of research groups}

150 research groups

37 institutions

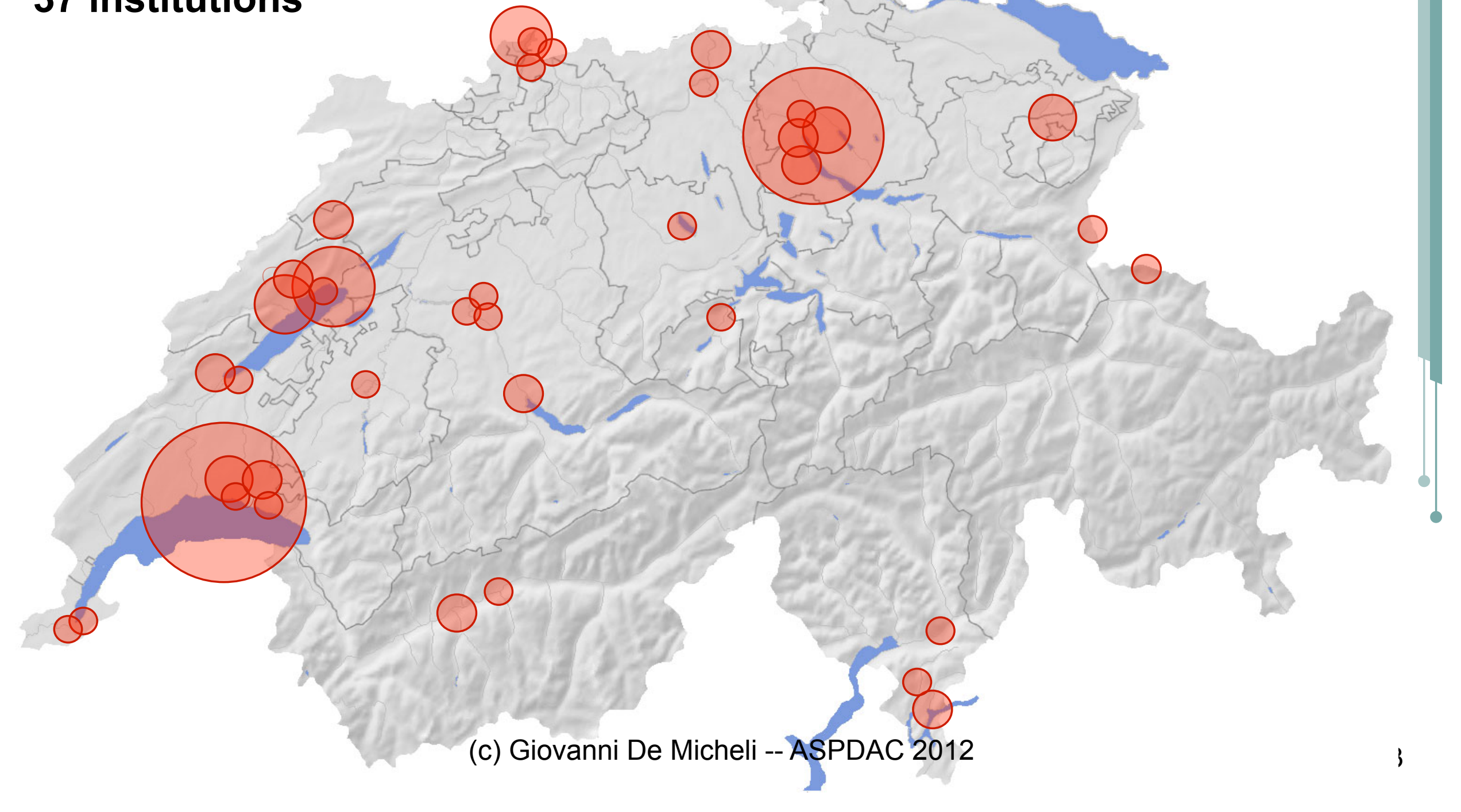




\section{Distribution of research groups}

\section{0 research groups}

\section{7 institutions}

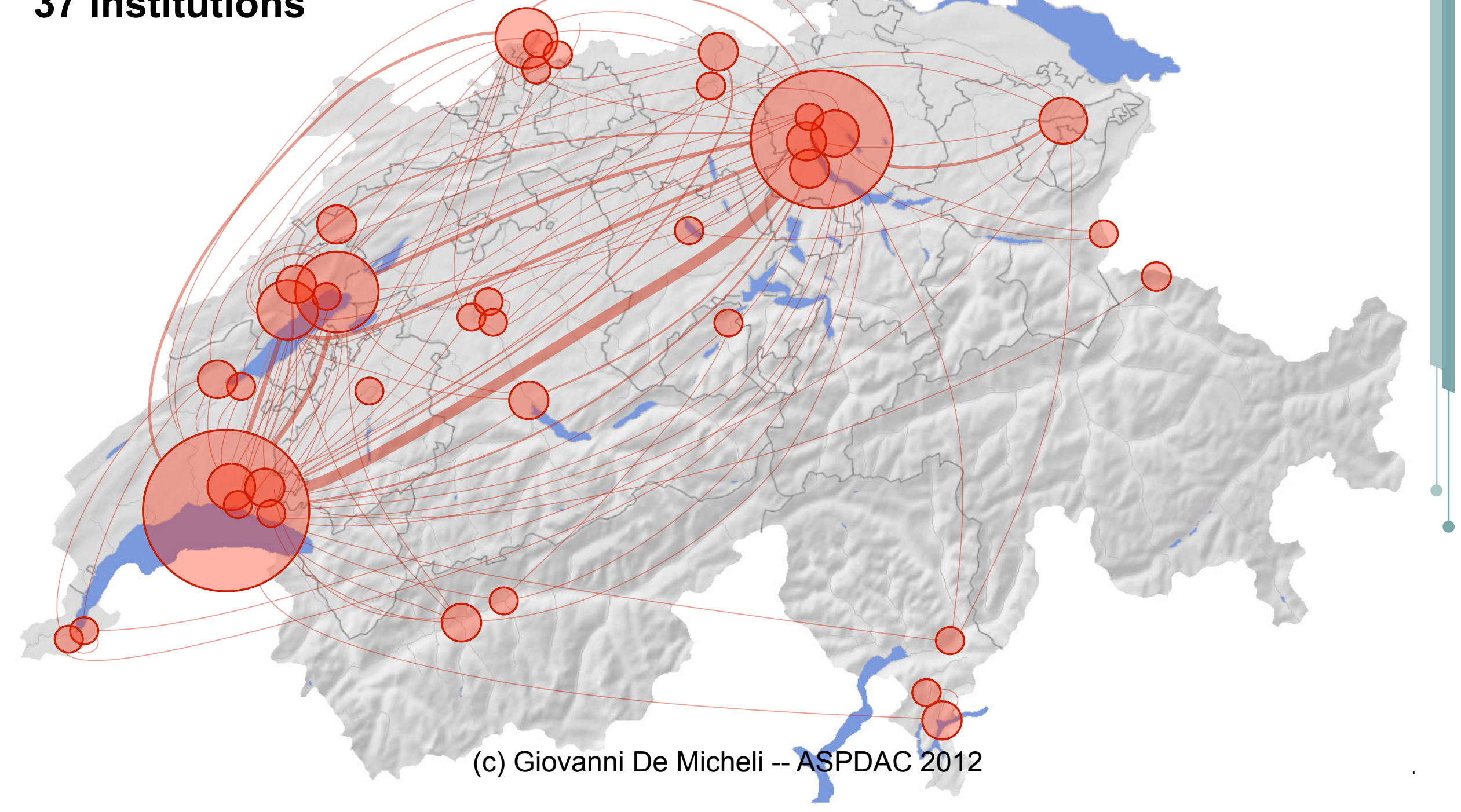




\section{E-Health}

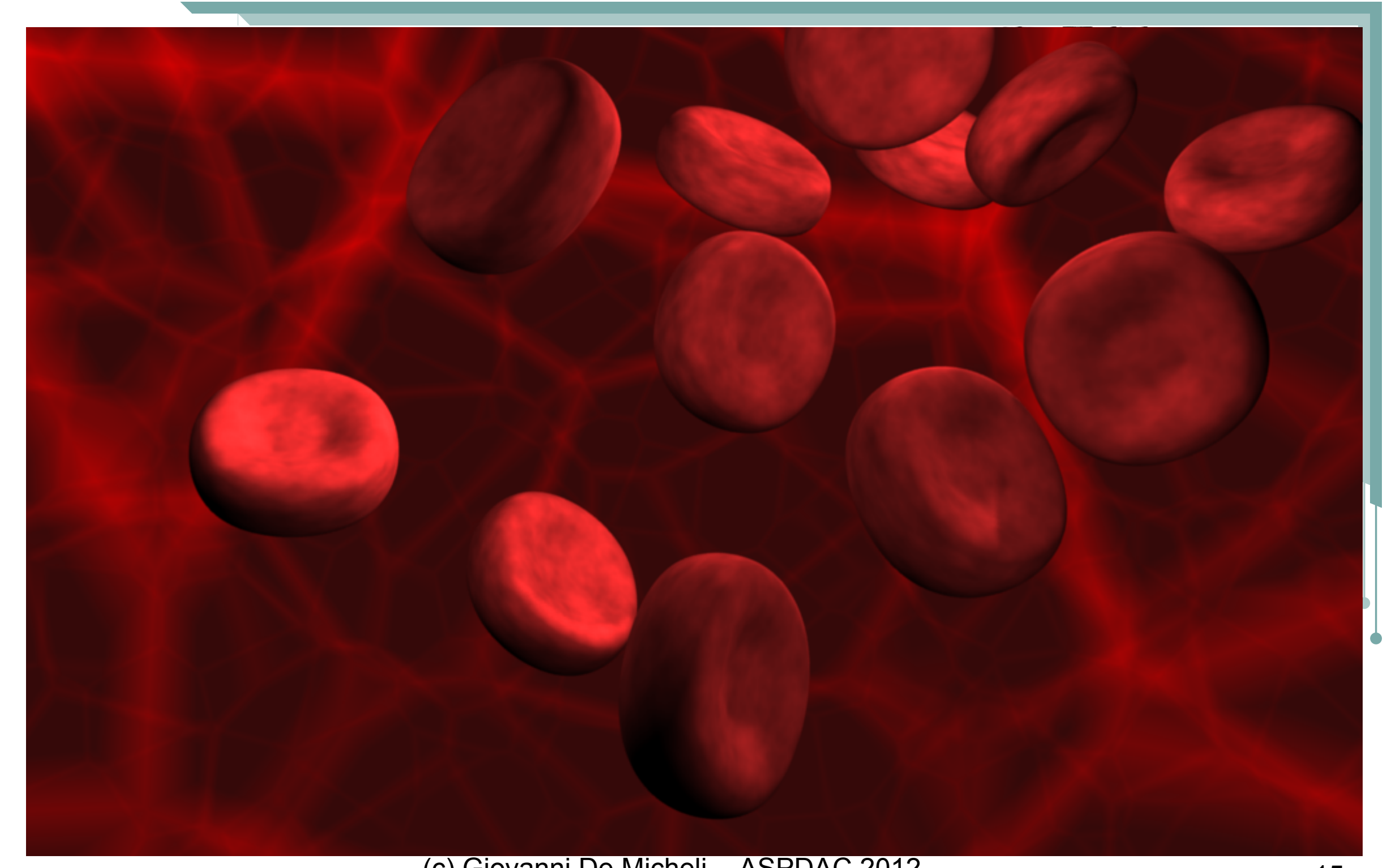




\section{Implantable/wearable system for online Giovanni De Micheli monitoring of human metabolic conditions (EPFL)}

\begin{tabular}{l|l} 
Goal: & $\begin{array}{l}\text { Study an innovative } \\
\text { real-time monitoring system for human metabolism }\end{array}$
\end{tabular}

Currently available wearable systems for health monitoring are for glucose

Many different molecules are crucial to monitor: $>$ lactate

$>$ ATP

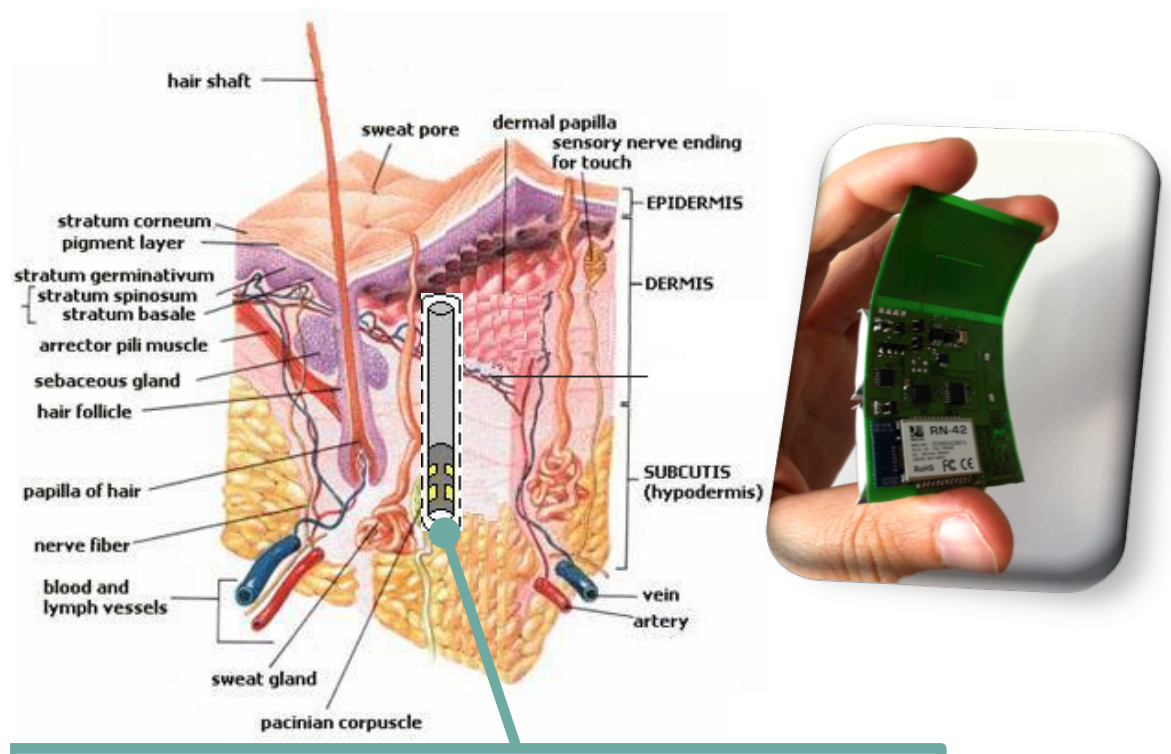

$>$ cholesterol

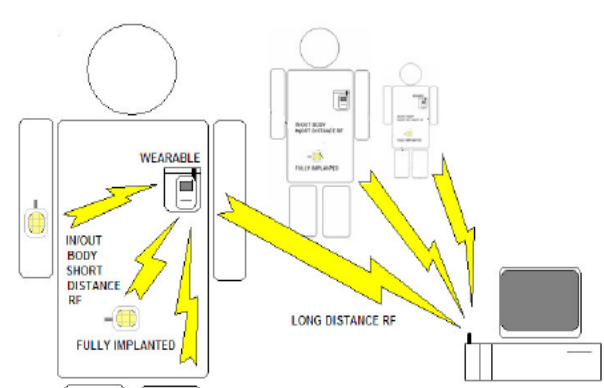

Cylinder: about $2 \mathrm{~mm}$ in diameter and below $20 \mathrm{~mm}$ in length 


\section{Medical platform design}

- Specific components

- Probes and electrodes

- Chambers and fluidic circuits

- Electronic components

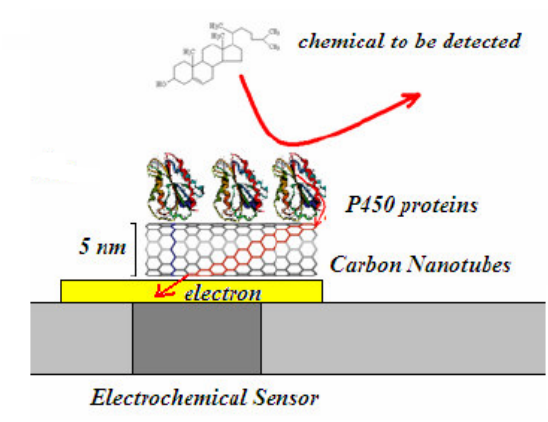

- Transconductance amplifier and data conversion

- Transmission and powering

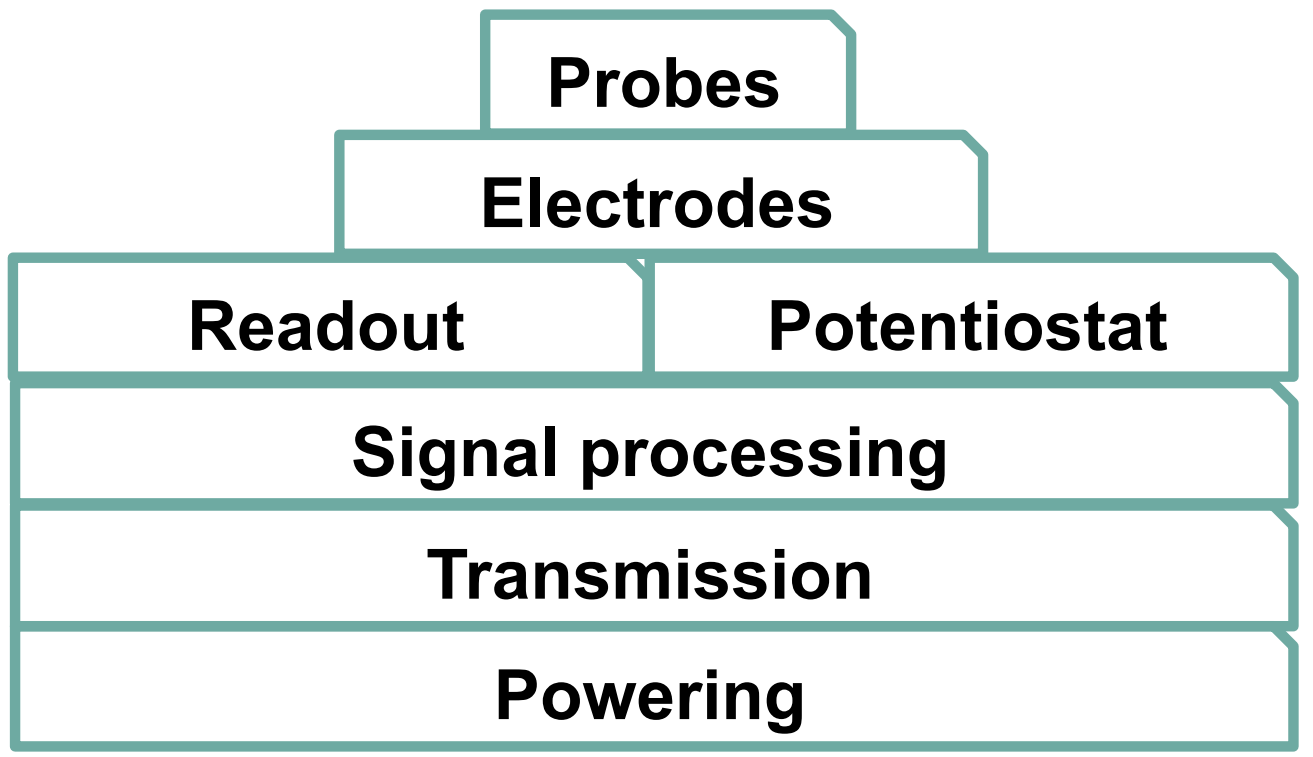

(c) Giovanni De Micheli -- ASPDAC 2012 


\section{Enhanced nano-bio-sensing}

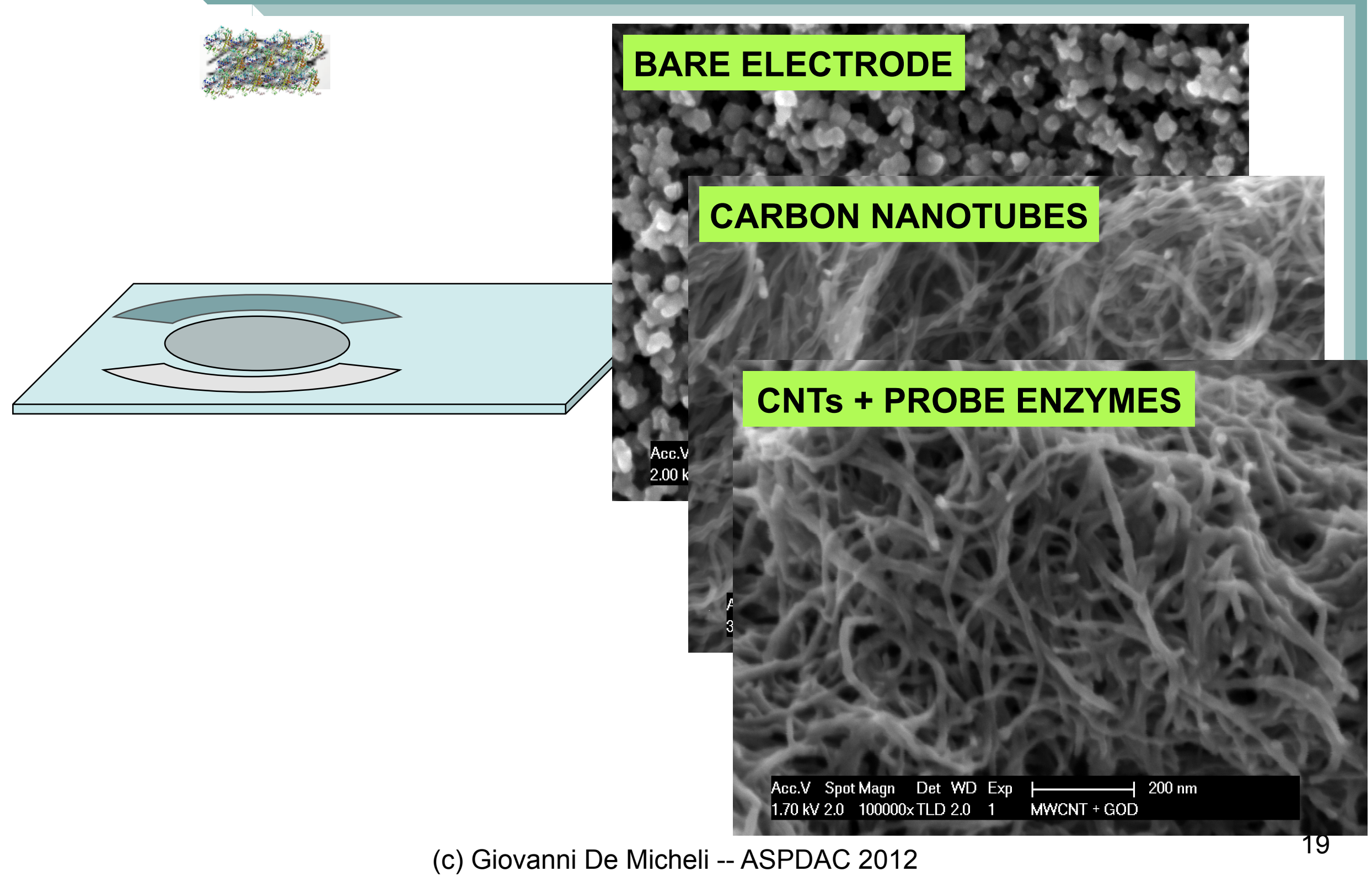




\section{Increased sensitivity}
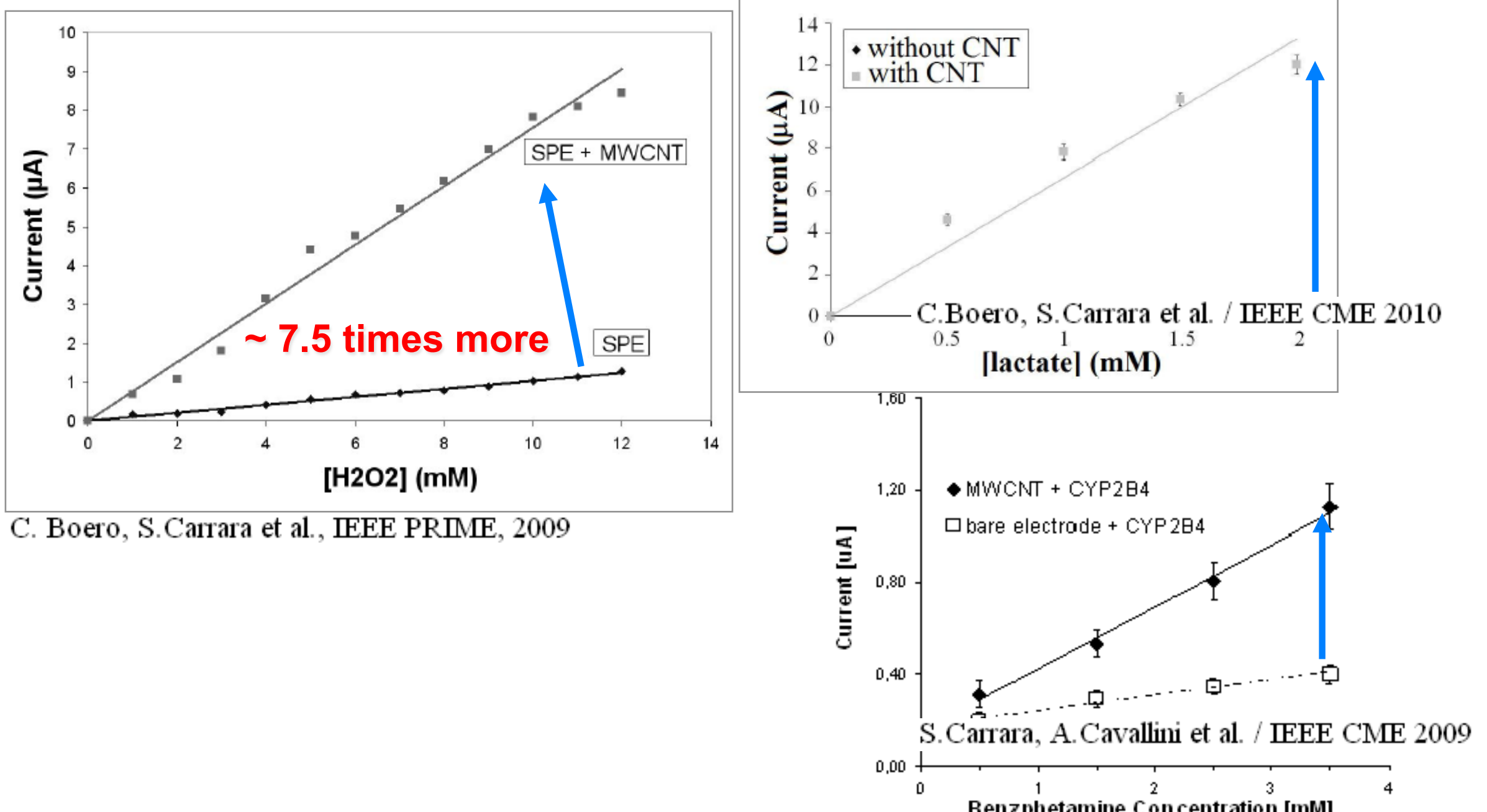

Sensor sensitivity is enhanced by nano-structuring the electrodes 


\section{Systems considerations}

- Multi-panel real-time sensing

- Use sensor array to do multiple bio-measures, along with temperature and $\mathrm{pH}$ sensing

- Low-noise transconductance amplification

- Low-power operation

- Data and power transmission

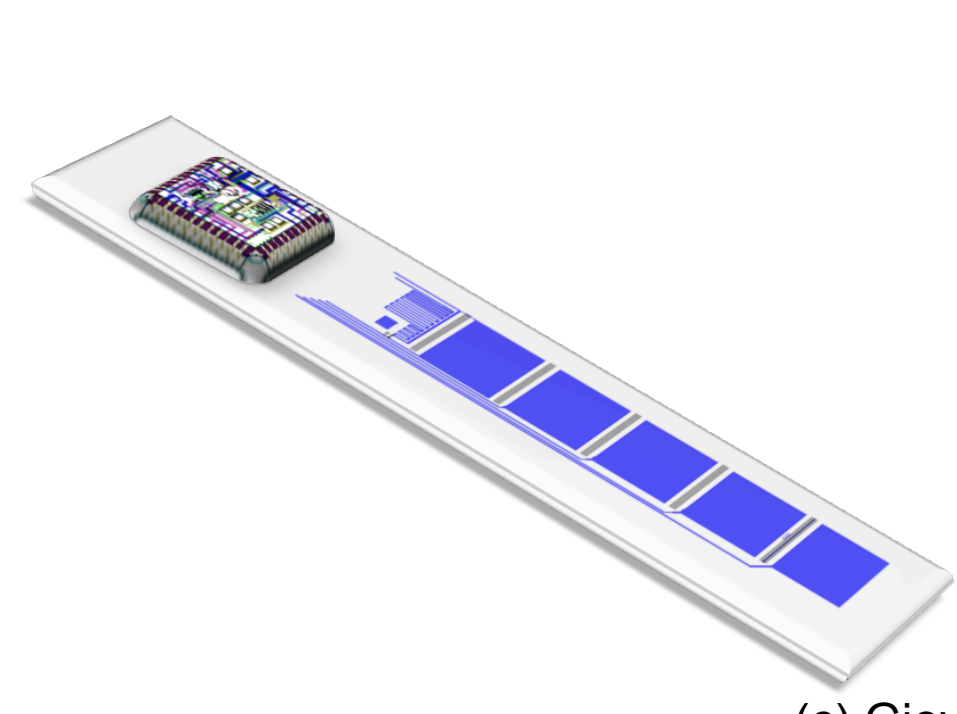

(c) Giovanni De Micheli -- ASPDAC 2012

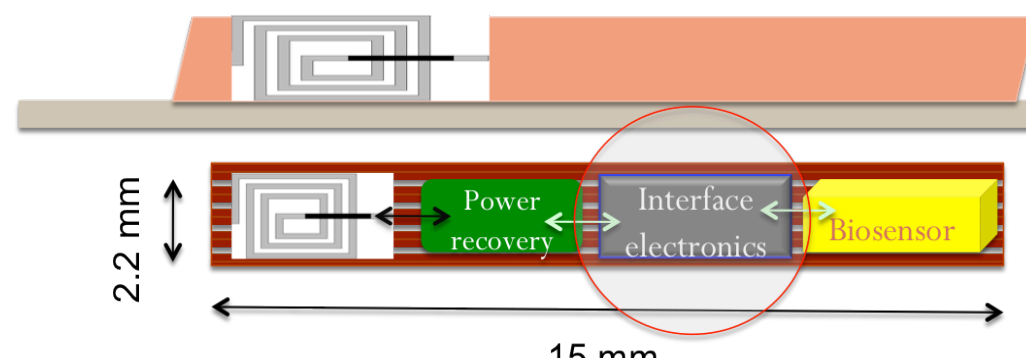

Patch

Skin

Implantable device 


\section{Other sensing platforms}

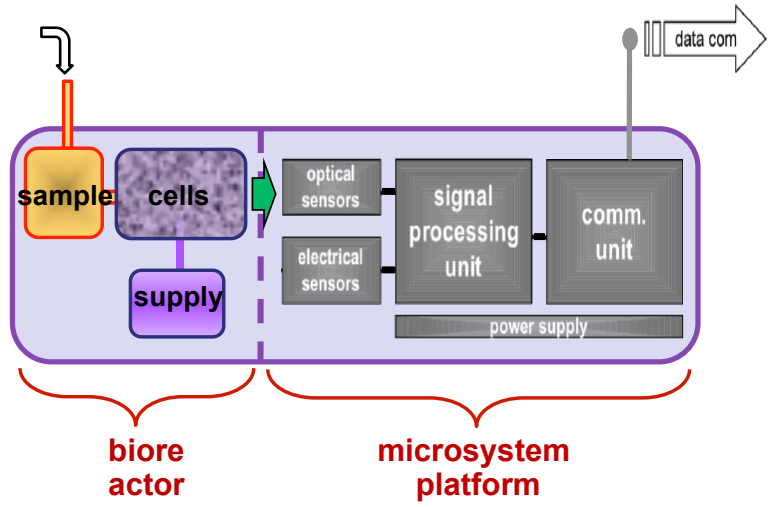

- LiveSense: Philippe Renaud (EPFL)

- Use living cells, fed by supply, to sense

- Optical and electrical monitoring

- Target: toxic compounds in water

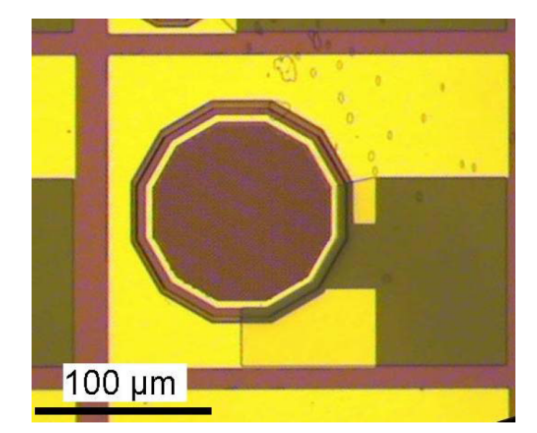

- IRSense: Jerome Faist (ETHZ)

- Use near-infrared absorbance measures

- Target: organic compounds in fluids

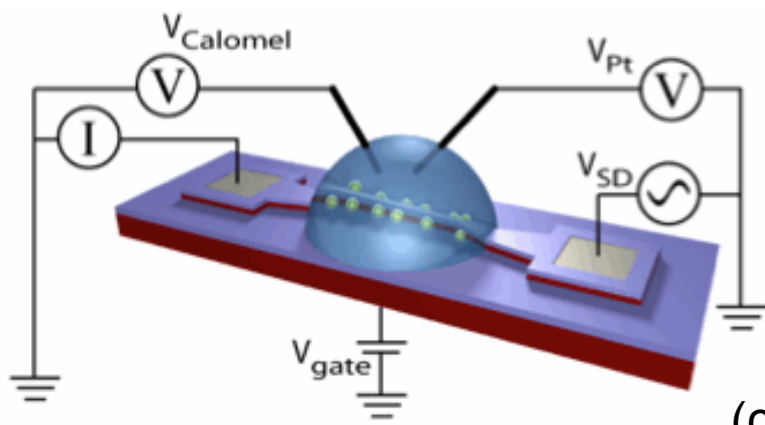

- NanowireSensor: c. Shönenberger (U. Basel)

- ISFETs based on silicon Nanowires

- Non-labeled sensing

(c) Giovanni De Micheli -- ASPDAC 2012 
Sensing capabilities close to the human body $\rightarrow$ monitor activity, motion, health... Incorporate built-in technological elements in our everyday textiles \& clothes

Existing E-textiles: low processability, wearing comfort, washability...

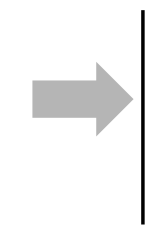

- design \& manufacture truly wearable functional clothes

- electronic fibers

- optical fibers

- transducer between optical \& electrical signals

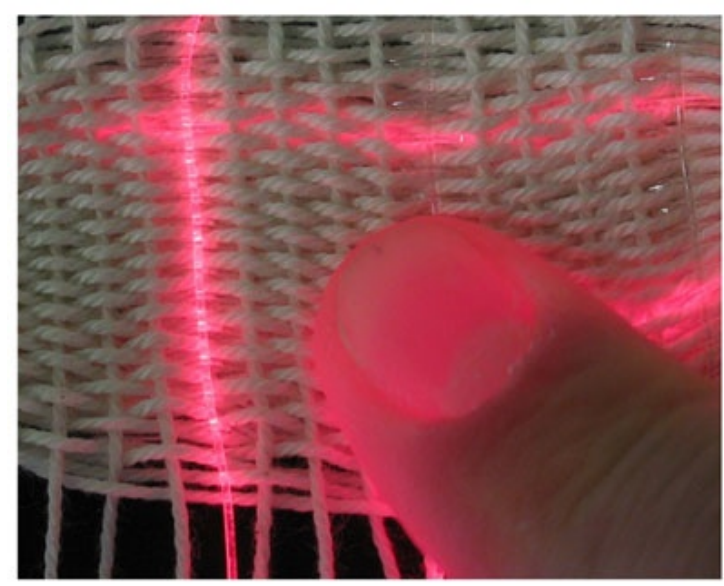

\section{Near infrared spectroscopy sensing}

Peripheral vascular diseases: $30 \%$ of adults

Early detection possible (near IR spectroscopy) but conventional sensors are cumbersome

Light wearable system in sock to monitor tissue oxygenation continuously \& non-invasively

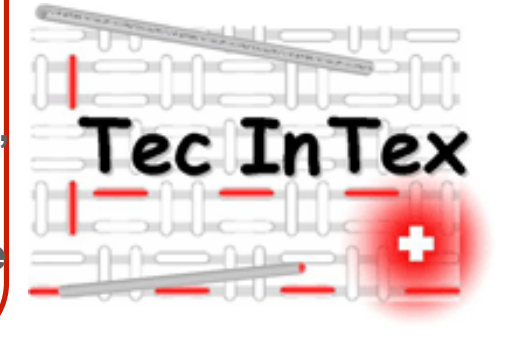

Intelligent underwear for paraplegic people

Pressure ulcers are serious problems for paraplegic and bed ridden patients

$\Rightarrow$ Build a comfortable device to detect the risk for pressure ulcers in order to enable preventive measures
EHH Eidgenössische Technische Hochschule Zürich
Swiss Federal Institute of Technology Zurich
* EMPA

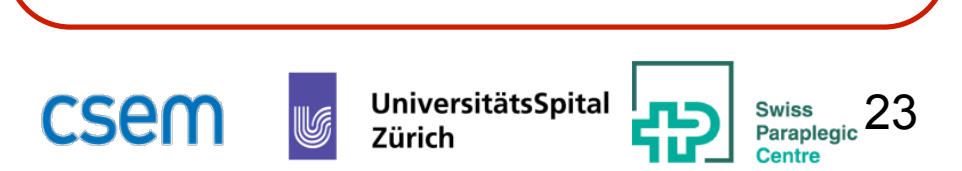




\section{Weaved optical sensor design}

- Modify optical fibers with sensitive porous layer

- Specific to biomarkers

- pH sensors (variation in color)

- Detection based on variation of light absorbance

- Fibers, detectors and light sources into fabric

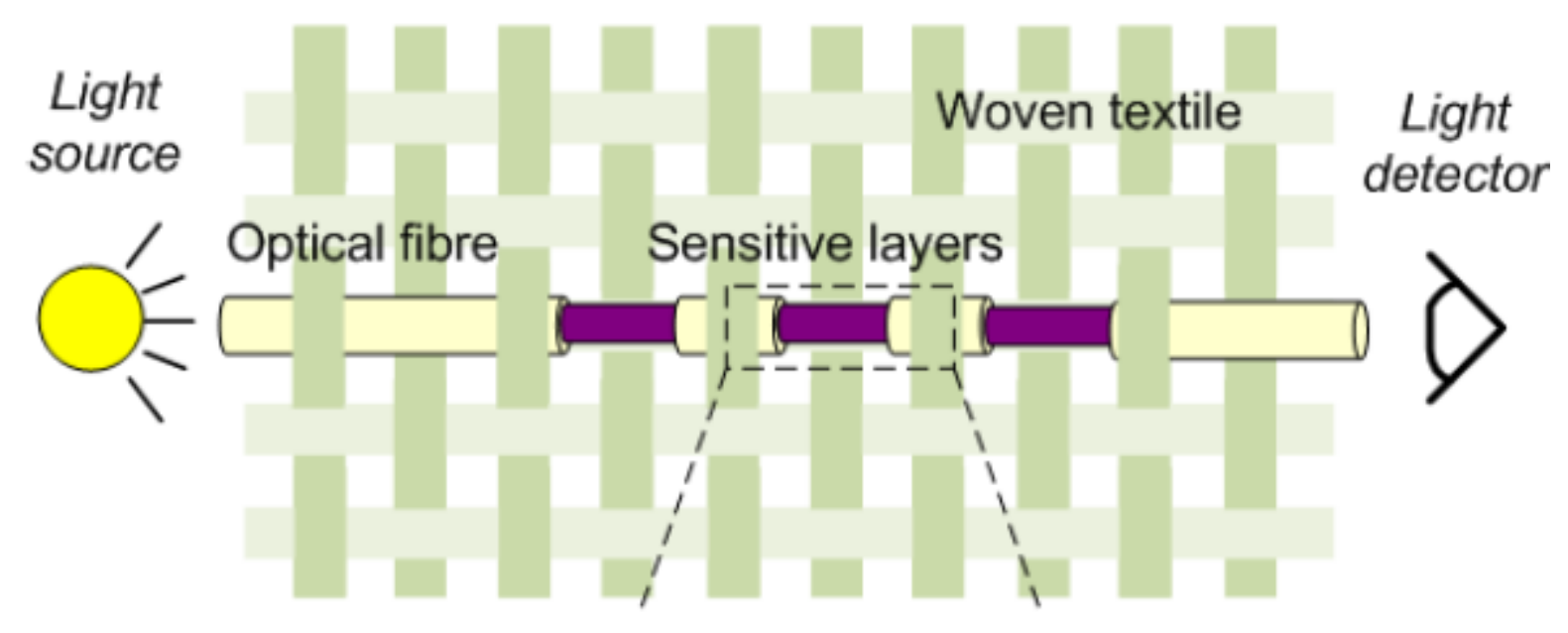

(c) Giovanni De Micheli -- ASPDAC 2012 


\section{Weaved electrical fabric}

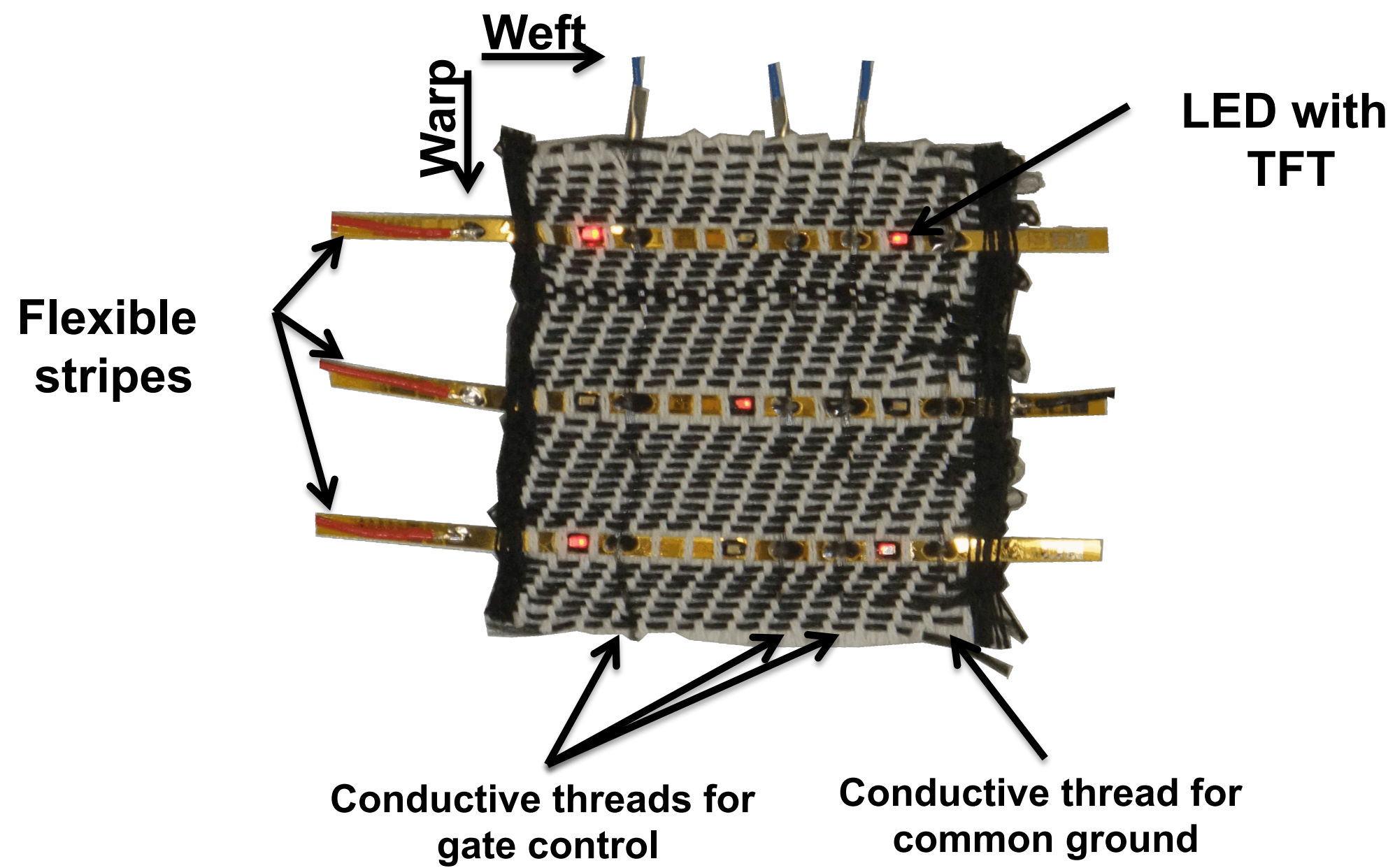




\section{Weaved electrical fabric}

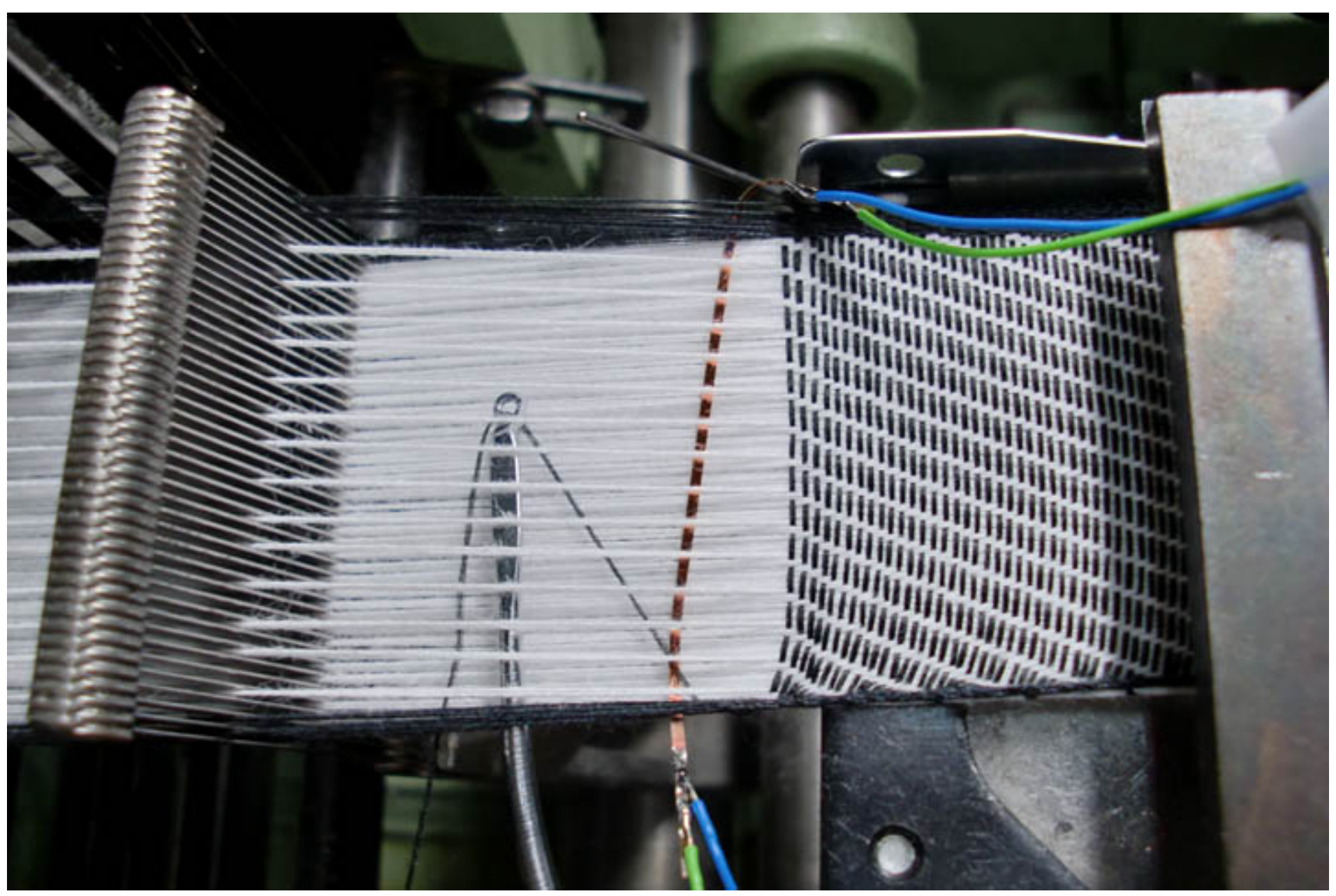

(c) Giovanni De Micheli -- ASPDAC 2012 


\section{Applications and demonstrators}

- NIRS (Near Infrared Spectroscopy) in socks

- Early detection and treatment of peripheral vascular disease (PVD)

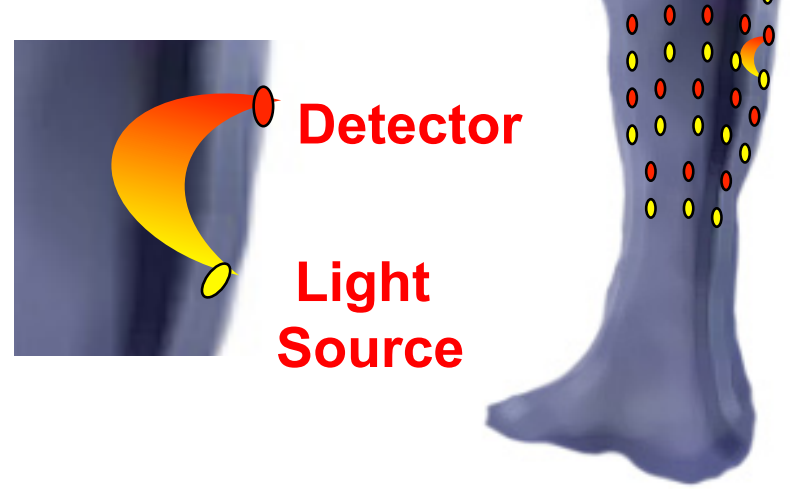
enough 0 lack of $\mathrm{O}$

- Intelligent underwear for paraplegic people to prevent and to treat ulcer

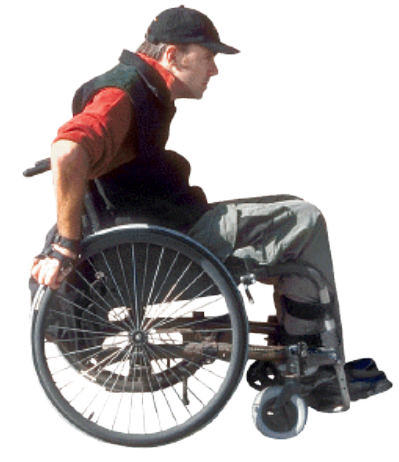

High decubitus risk 


\section{Other medical projects}

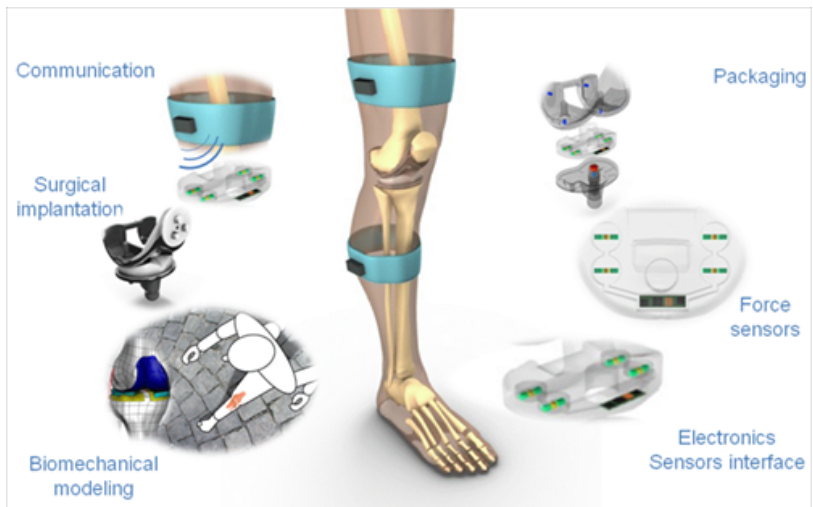

Monitor knee implants

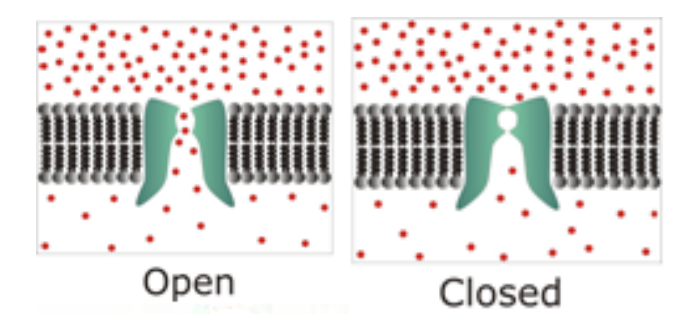

Intelligent drug delivery

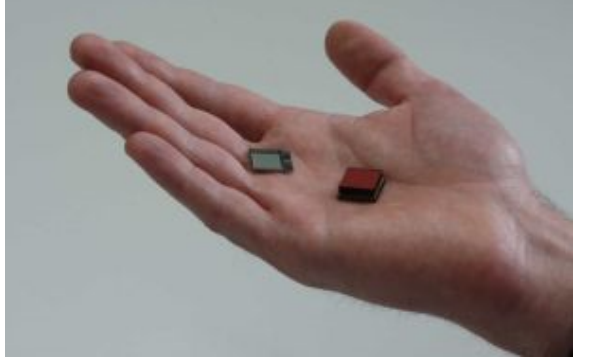

Mini x-ray sources

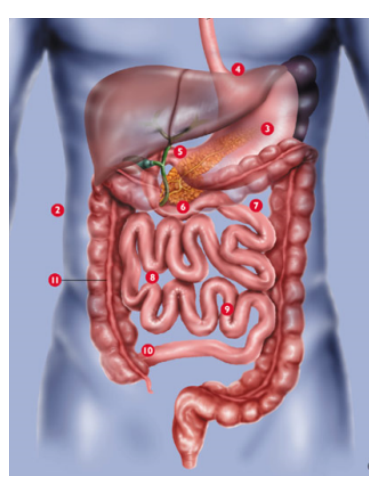

Organ emulation

(c) Giovanni De Micheli -- ASPDAC 2012 


\section{E-Environment}

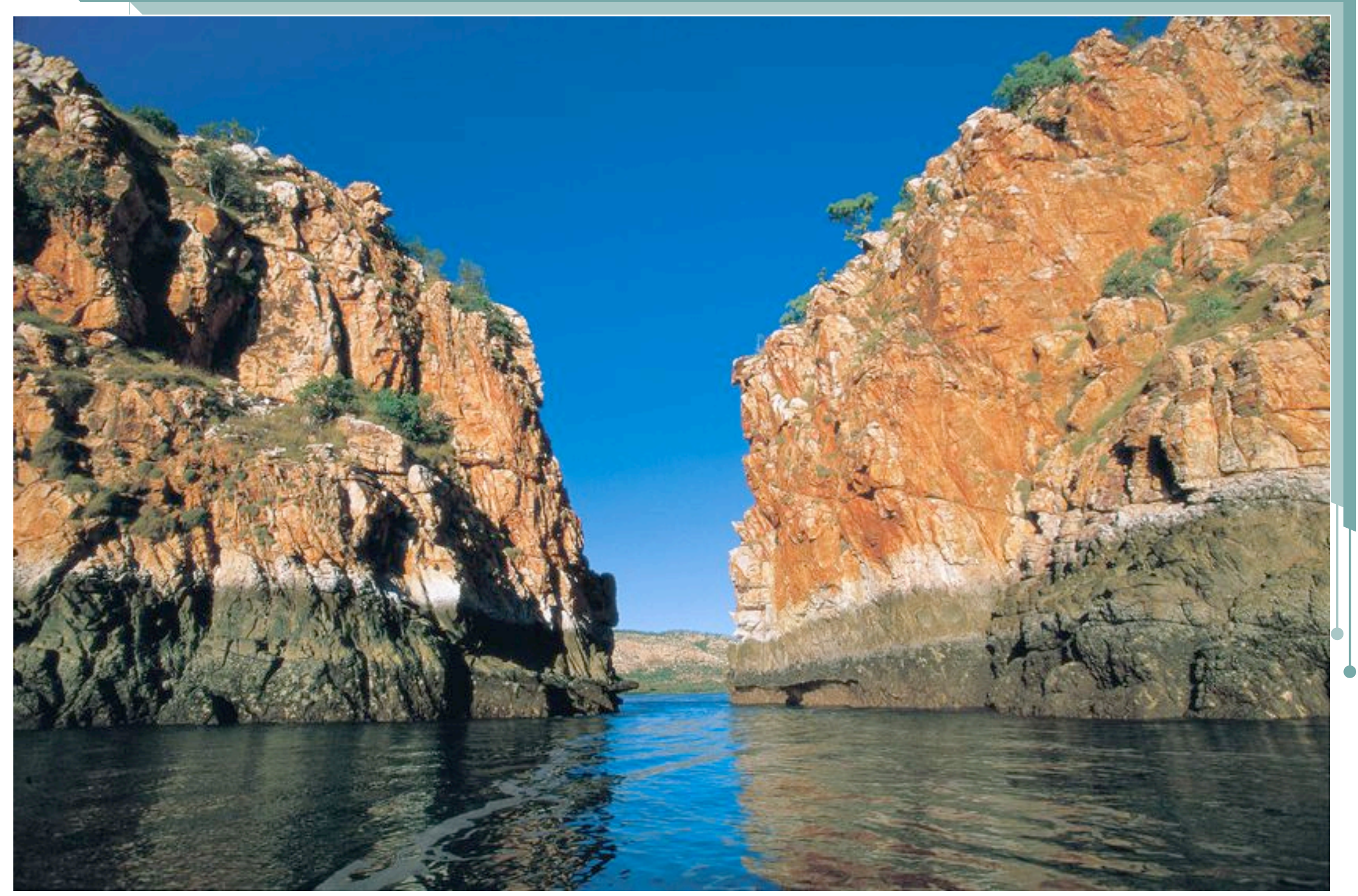

(c) Giovanni De Micheli -- ASPDAC 2012 


\section{Environment systems}

Large-scale distribution of auto-configurable networks of sensor nodes

to sense - network - inform - actuate - interact with the physical environment, the devices and humans

Next generation information technology, with devices that are... • highly distributed

\begin{tabular}{|l|}
\hline Application areas \\
\hline - Environmental monitoring \\
- Smart buildings \& workplaces \\
- Smart transportation systems \\
- Virtual-world applications \\
\hline
\end{tabular}
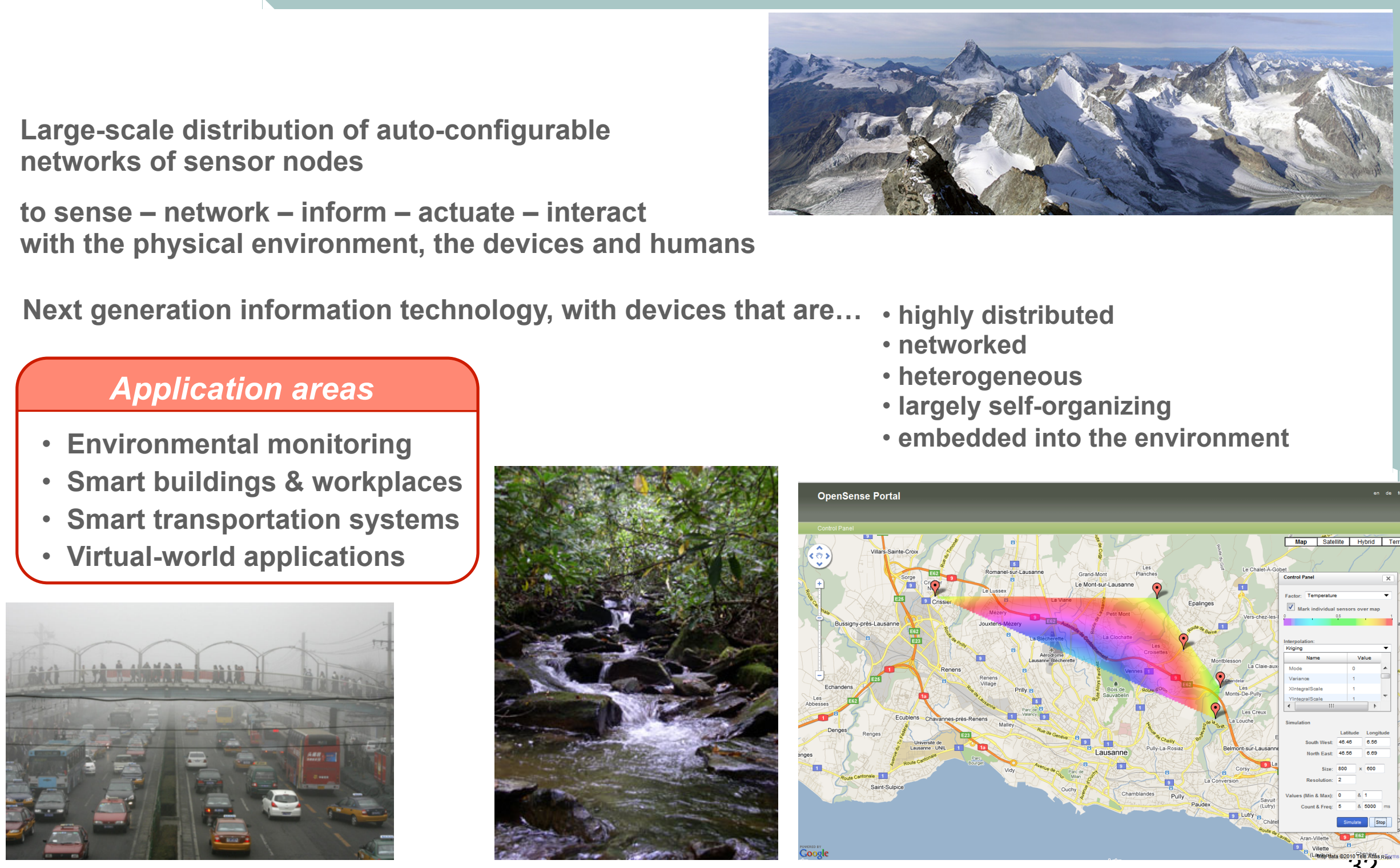

- networked

- heterogeneous

- largely self-organizing

- embedded into the environment

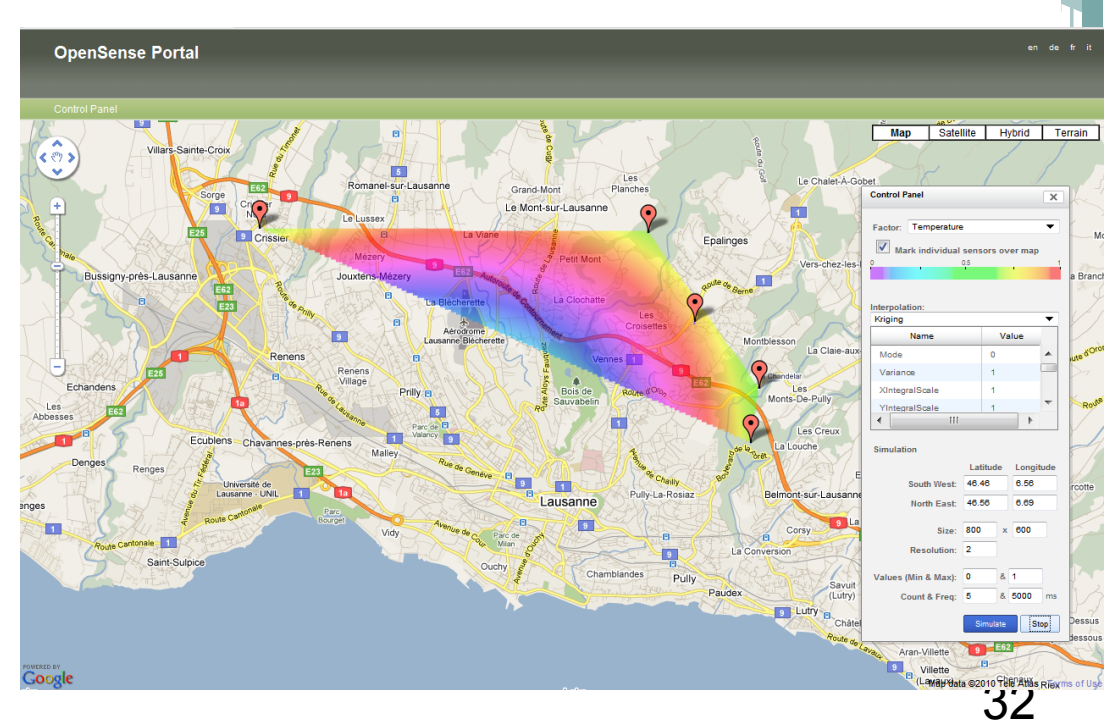


Community driven, large-scale air pollution measurement in urban environments

- Important problem: air pollution

- Few monitoring stations measure pollutants

- Important technical opportunities \& challenges

- Massive measurements that exploit:

- wireless sensor networks

- mobile stations

- community involvement

- More data, more noise... also more redundancy

- Can we produce better quality data?

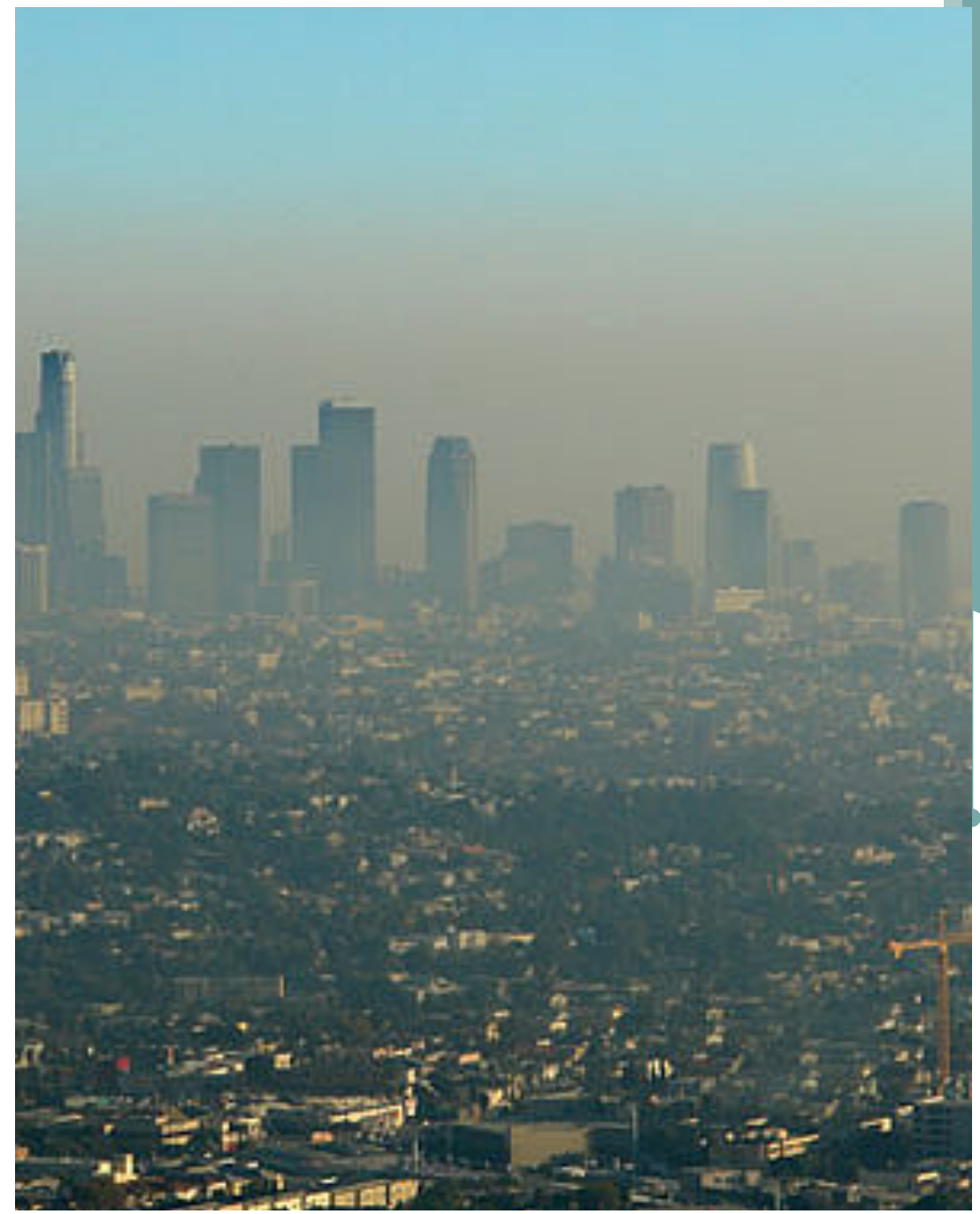




\section{OpenSense: challenges}

SENSING SYSTEM
$\mathrm{Z}$
$\mathrm{z}$
$\mathrm{z}$
heterom many wireless, mobile,
measurements ...

INFORMATION SYSTEM

... to reliable, understandable and

Web-accessible real-time information

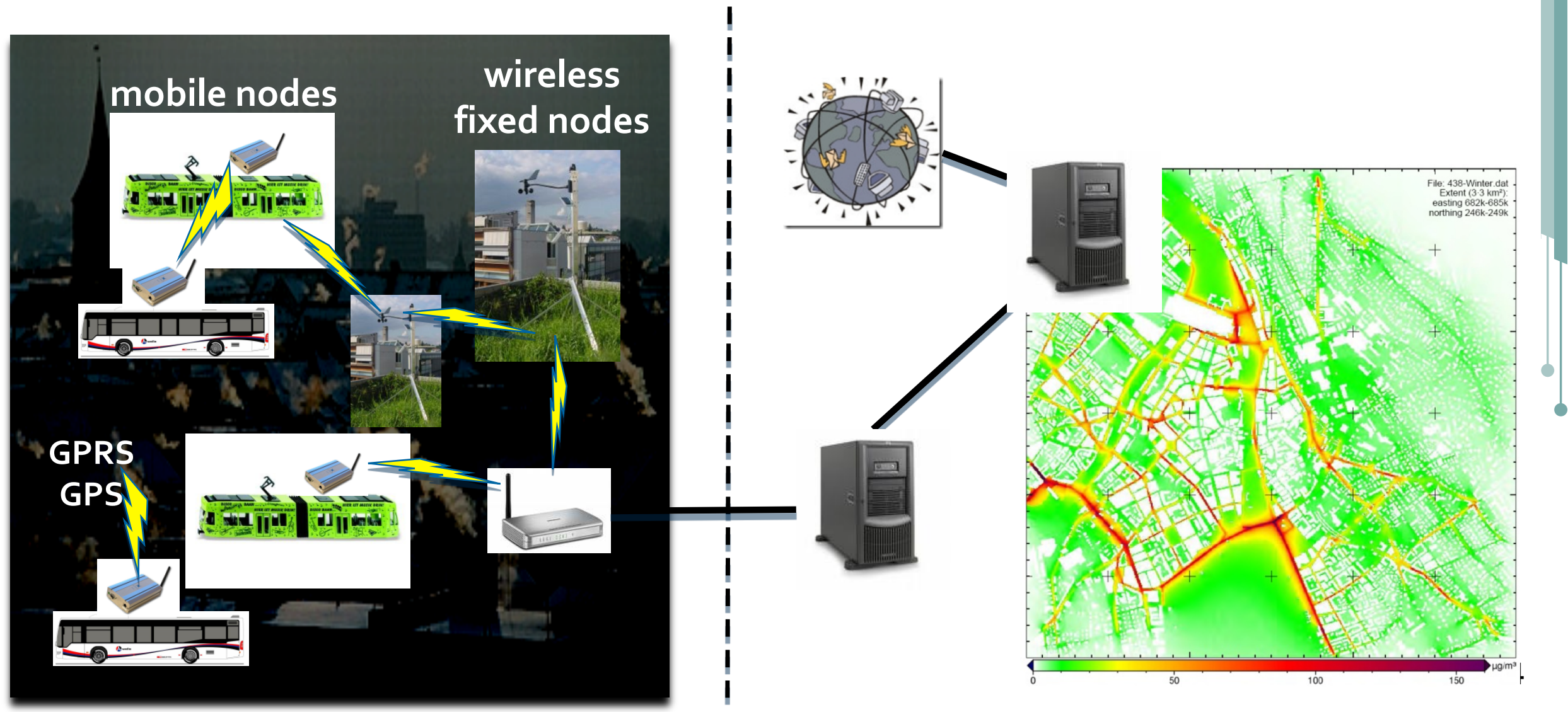




\section{Sensing infrastructure}
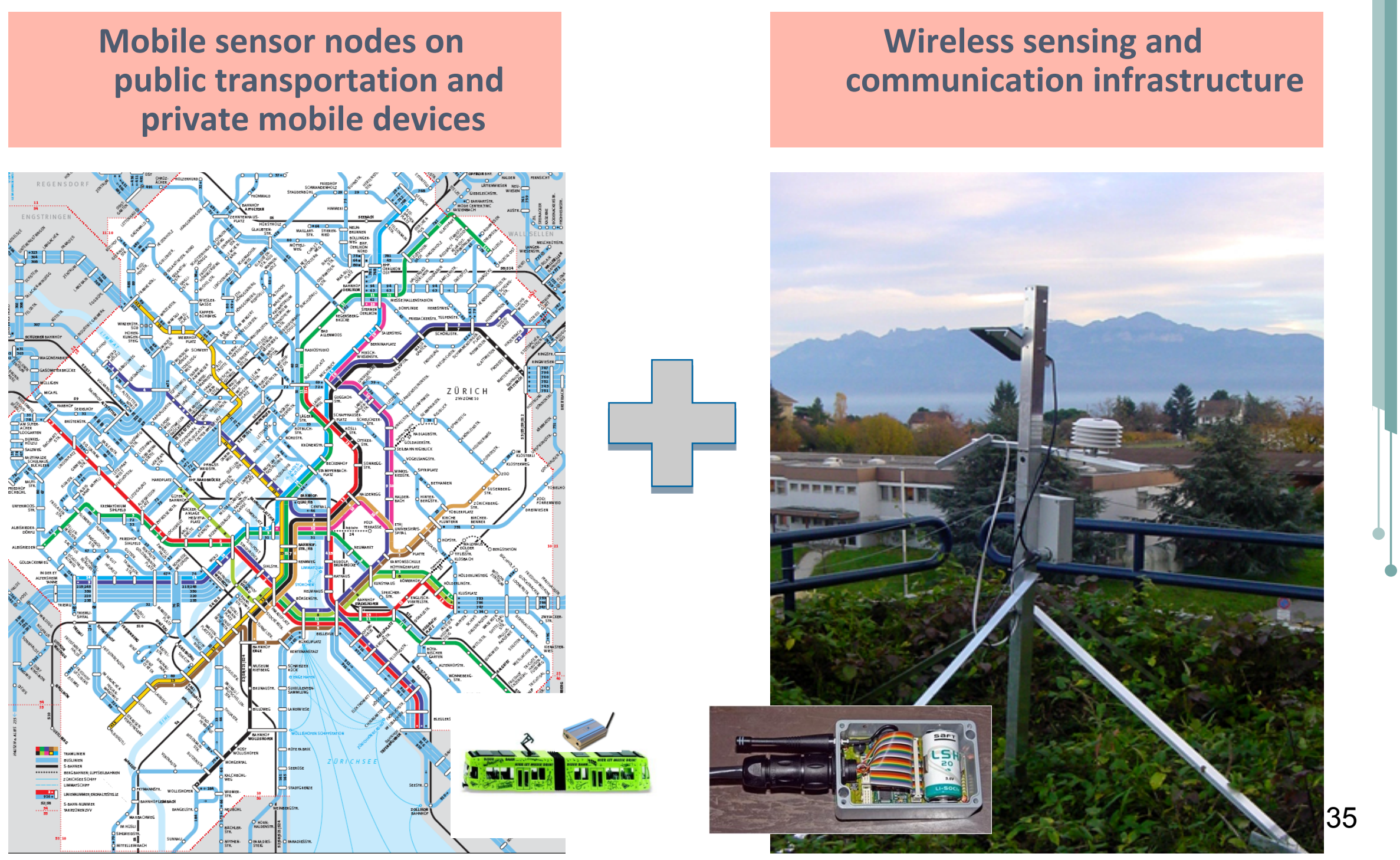


\section{Lausanne: stationary infrastructure}

- 2 prototype stationary stations

- NO2 (2 sensors), CO (2 sensors), Humidity, Temperature

- Solar panel powered

- 1 station next to Nabel

- 12 stations deployed in 2012

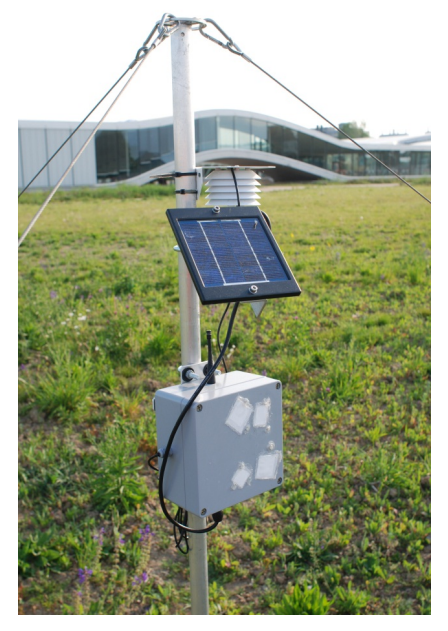

EPFL campus

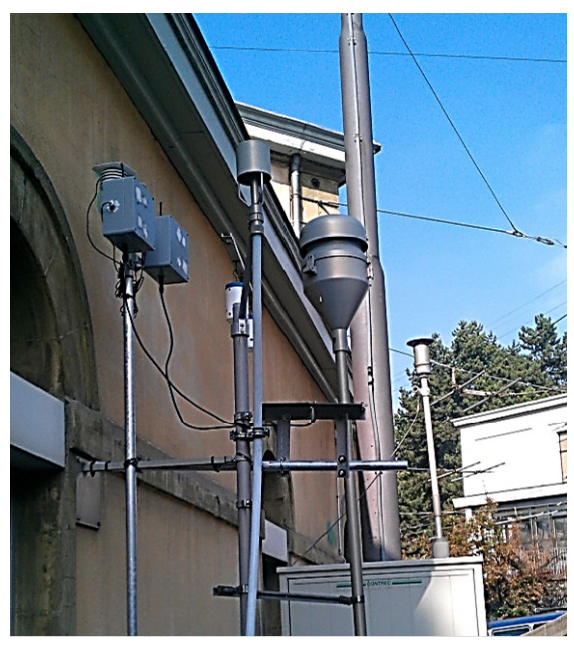

Lausanne Nabel station

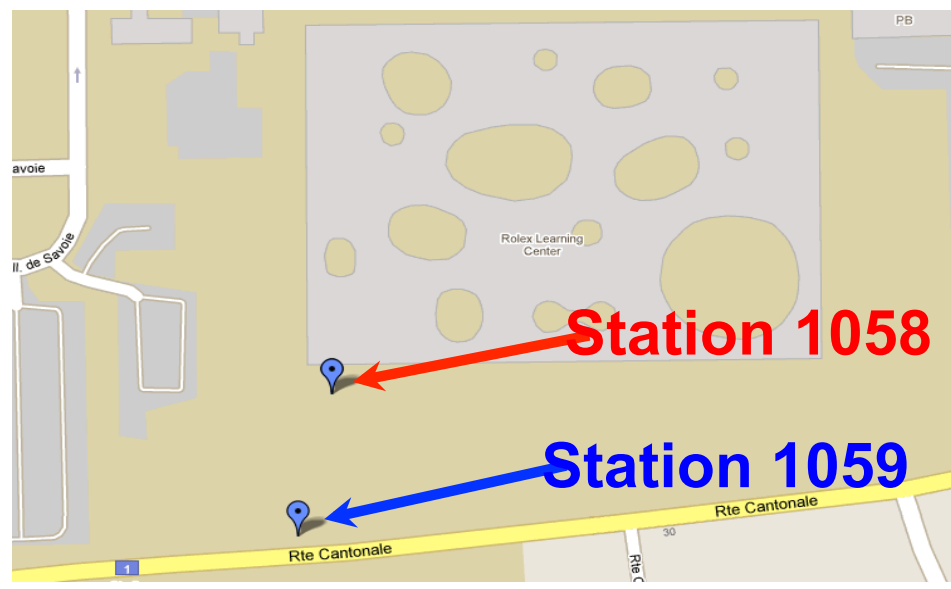

NO2 in Relation to Road

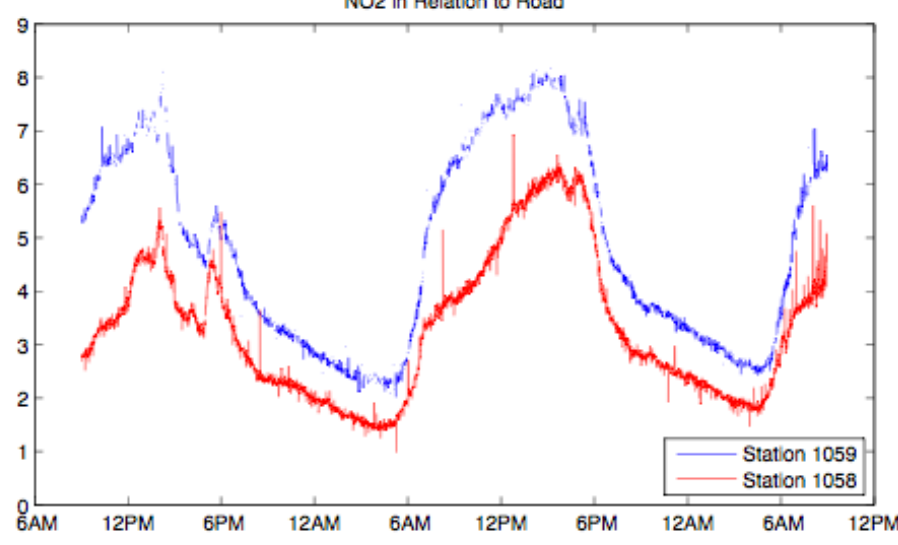

$10 \mathrm{~m}$ distance result in significant difference

(c) Giovanni De Micheli -- ASPDAC 2012 


\section{Lausanne: mobile infrastructure}

- 1 prototype station mounted on bus

- NO2, CO (2 sensors), $\mathrm{CO} 2$, Humidity, Temperature

- Positioning module

- Powered by bus

- 8 mobile stations being deployed

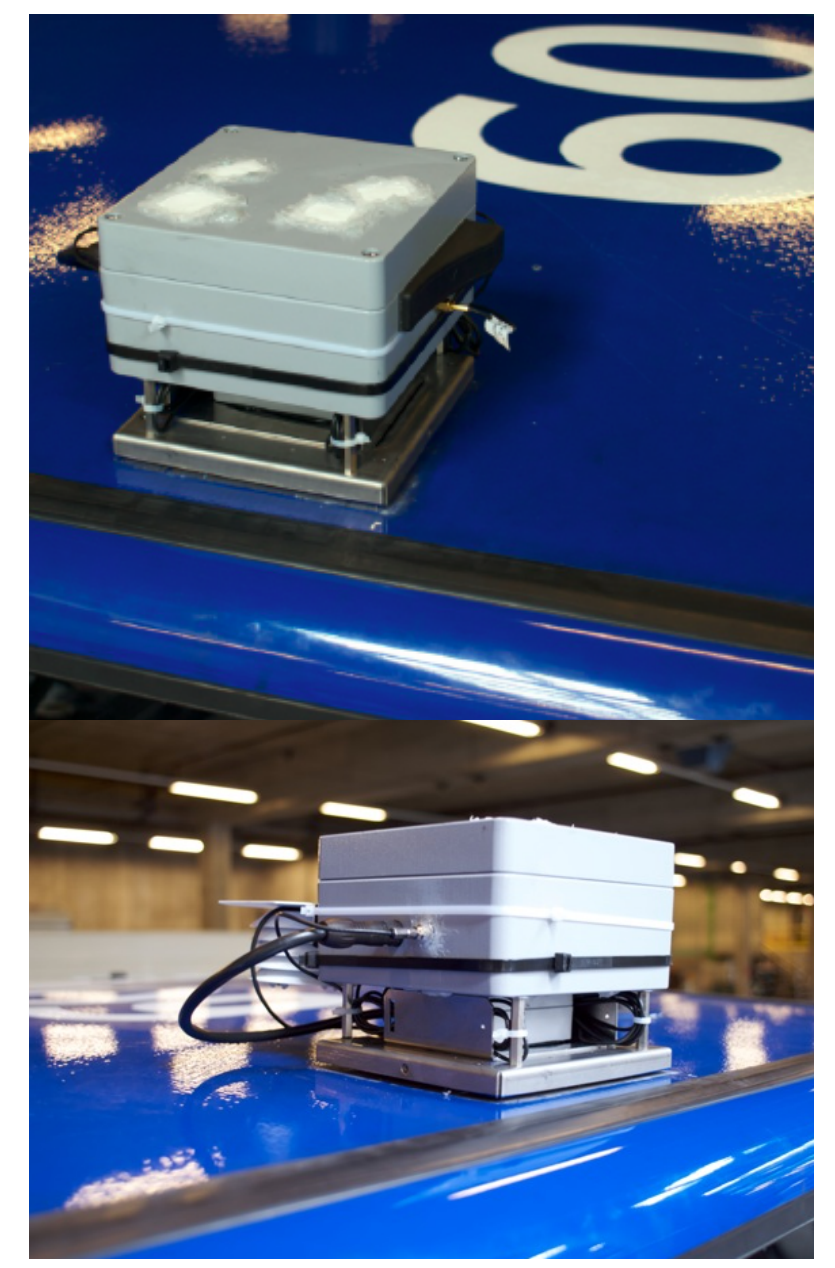

(c) Giovanni De Micheli -- ASPDAC 2012 


\section{Lausanne coverage}

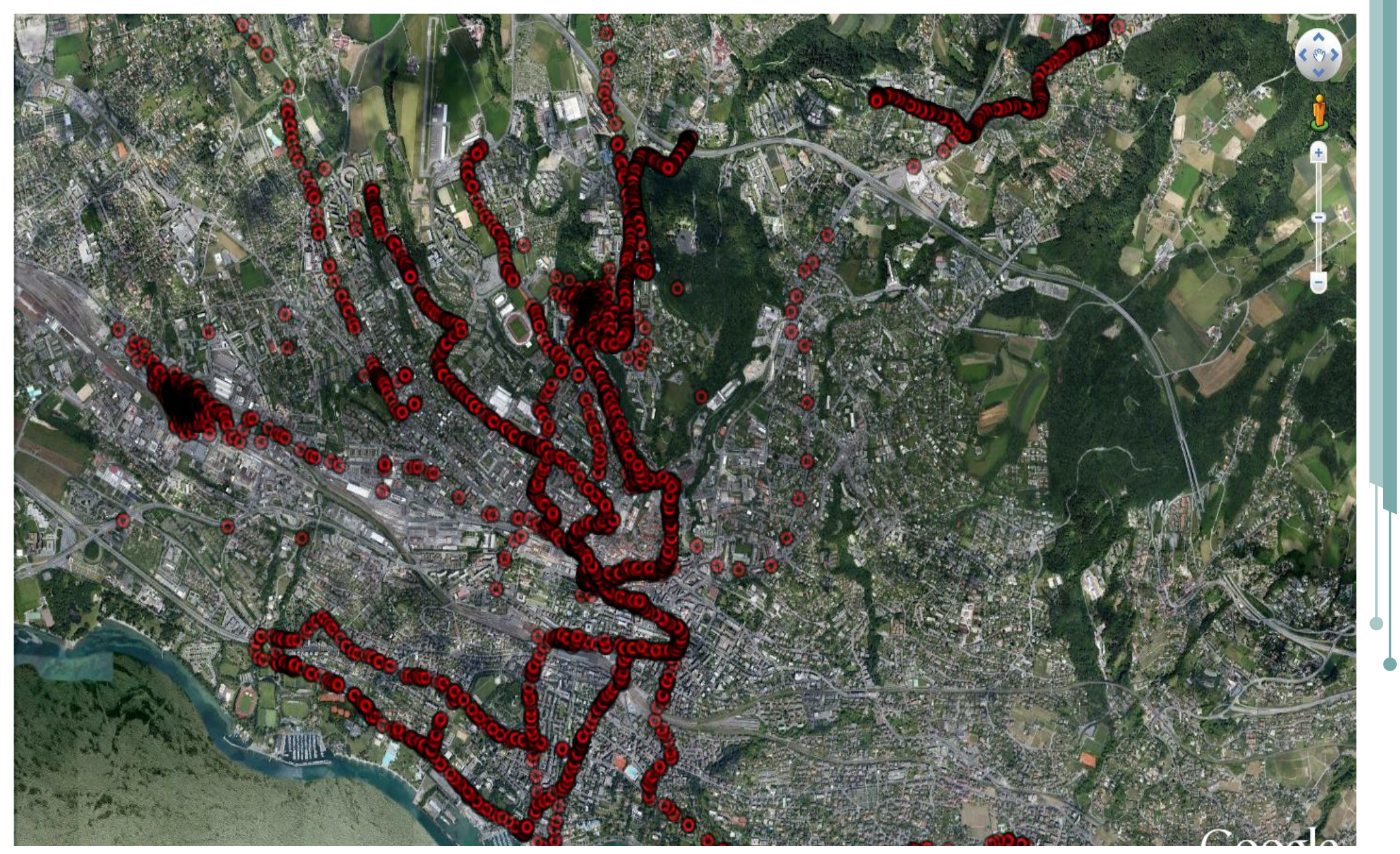

(c) Giovanni De Micheli -- ASPDAC 2012 


\section{OpenSense: scientific challenge}

Is massive sensing with large numbers of heterogeneous and mobile sensors technically feasible and practically useful?

\section{Use of correlations}

Need to compress, clean \& interpret the huge amount of data generated

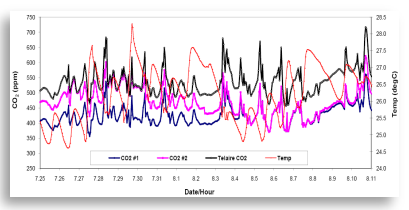

$\Rightarrow$ Identify and exploit spatial \& temporal correlations in sensor data
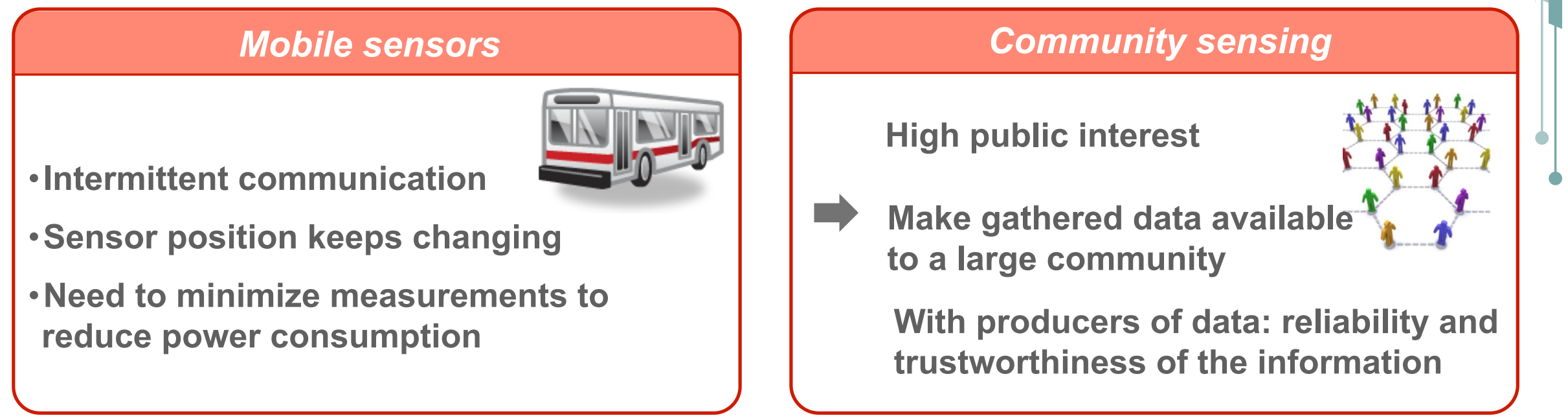

(c) Giovanni De Micheli -- ASPDAC 2012 


\section{EIH}

Eidgenössische Technische Hochschule Zürich Swiss Federal Institute of Technology Zurich

Universität Zürich

GAMMA REMOTE SENSING

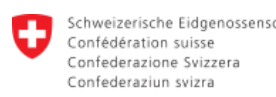

confederaziun svizra

Swiss Confederation

Federal Office for the Environment FoEN

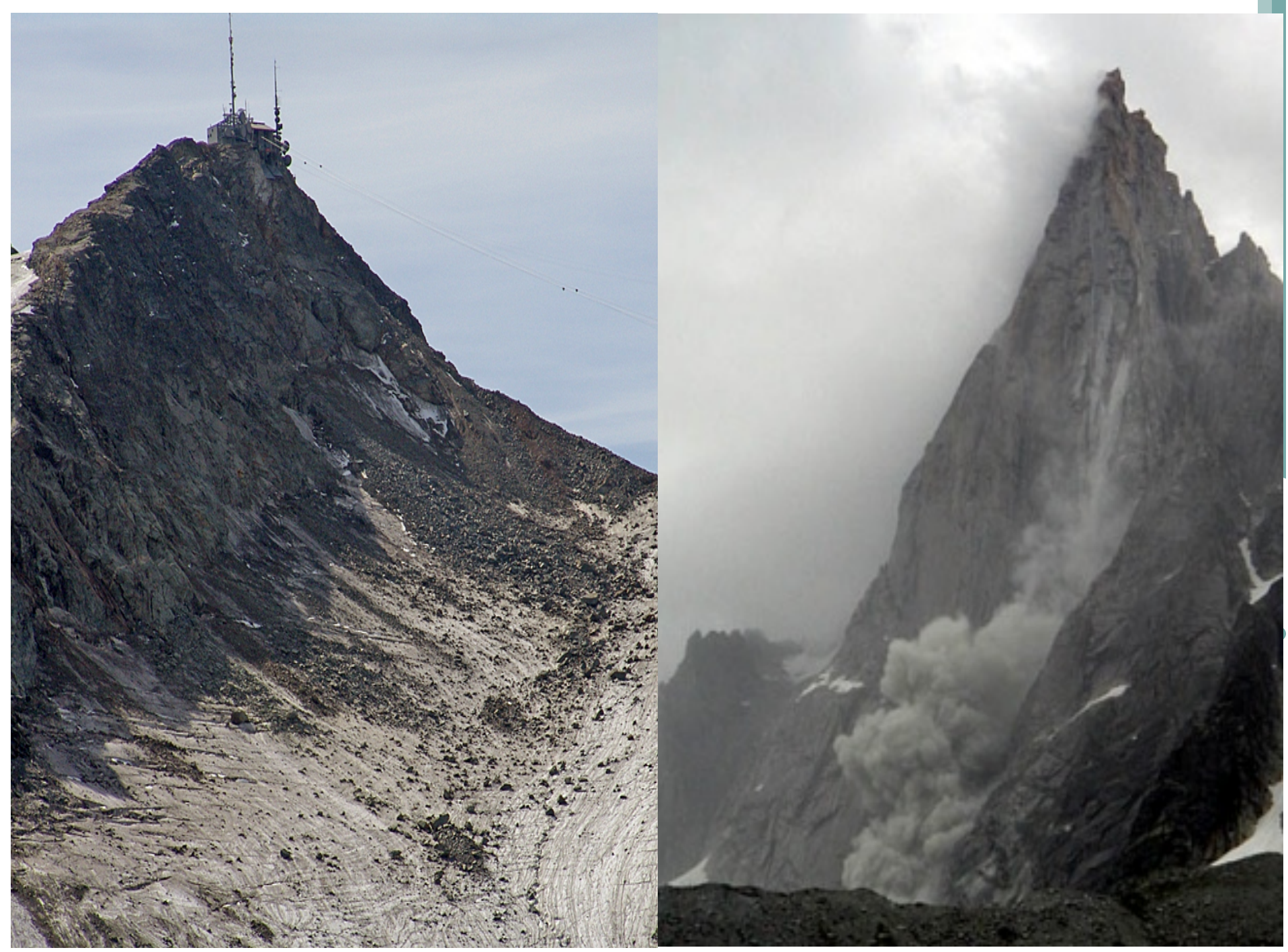




\section{X-Sense hypothesis}

- Anticipation environmental states and risk improved by

- A systematic combination of sensors at different temporal and spatial scale

- Wireless Sensor Networks

- Allows us to quantify mountain cryosphere phenomena and their response to climate change

- Can be used for safety critical applications in a hostile environment

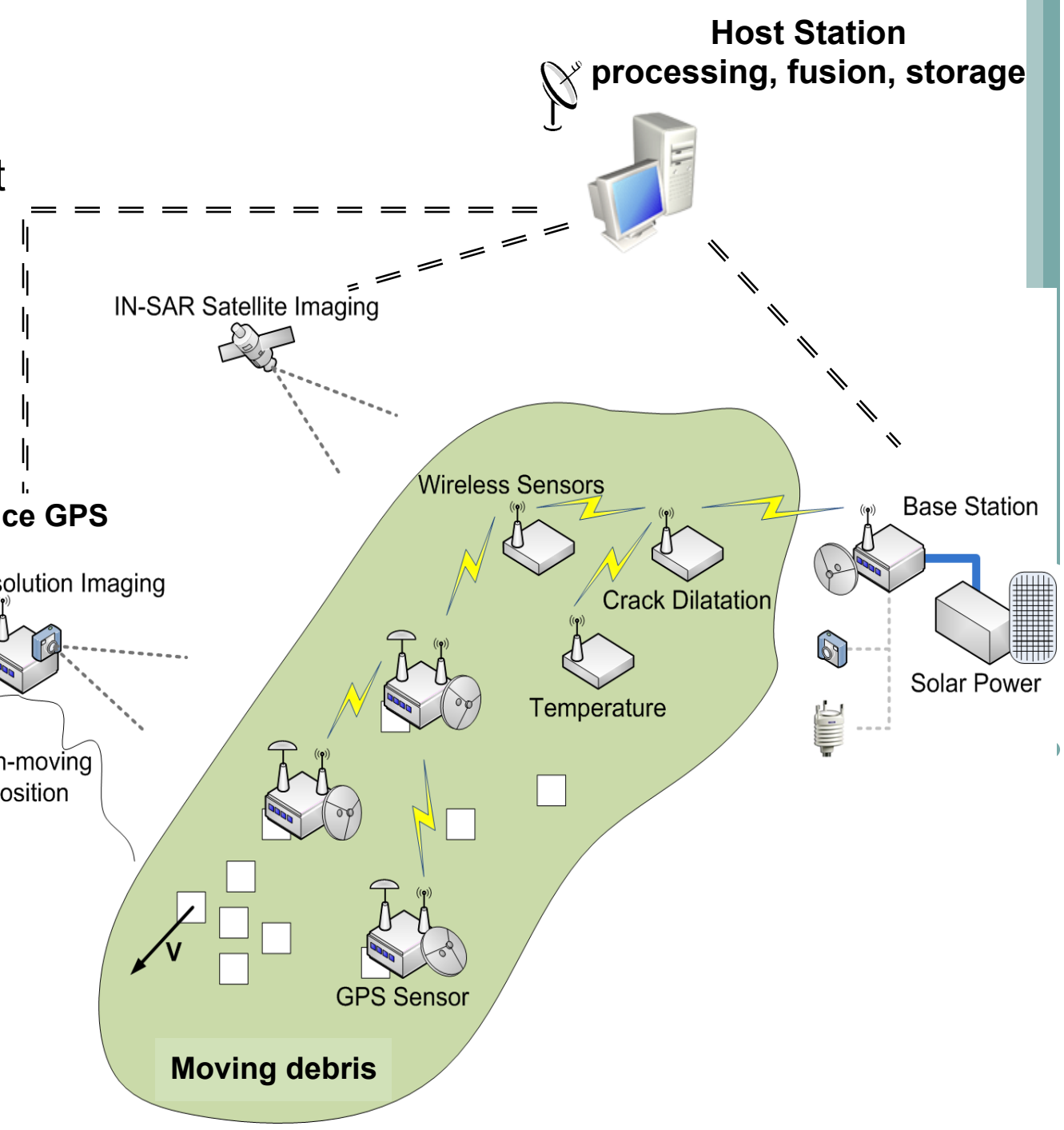




\section{X-Sense task structure}

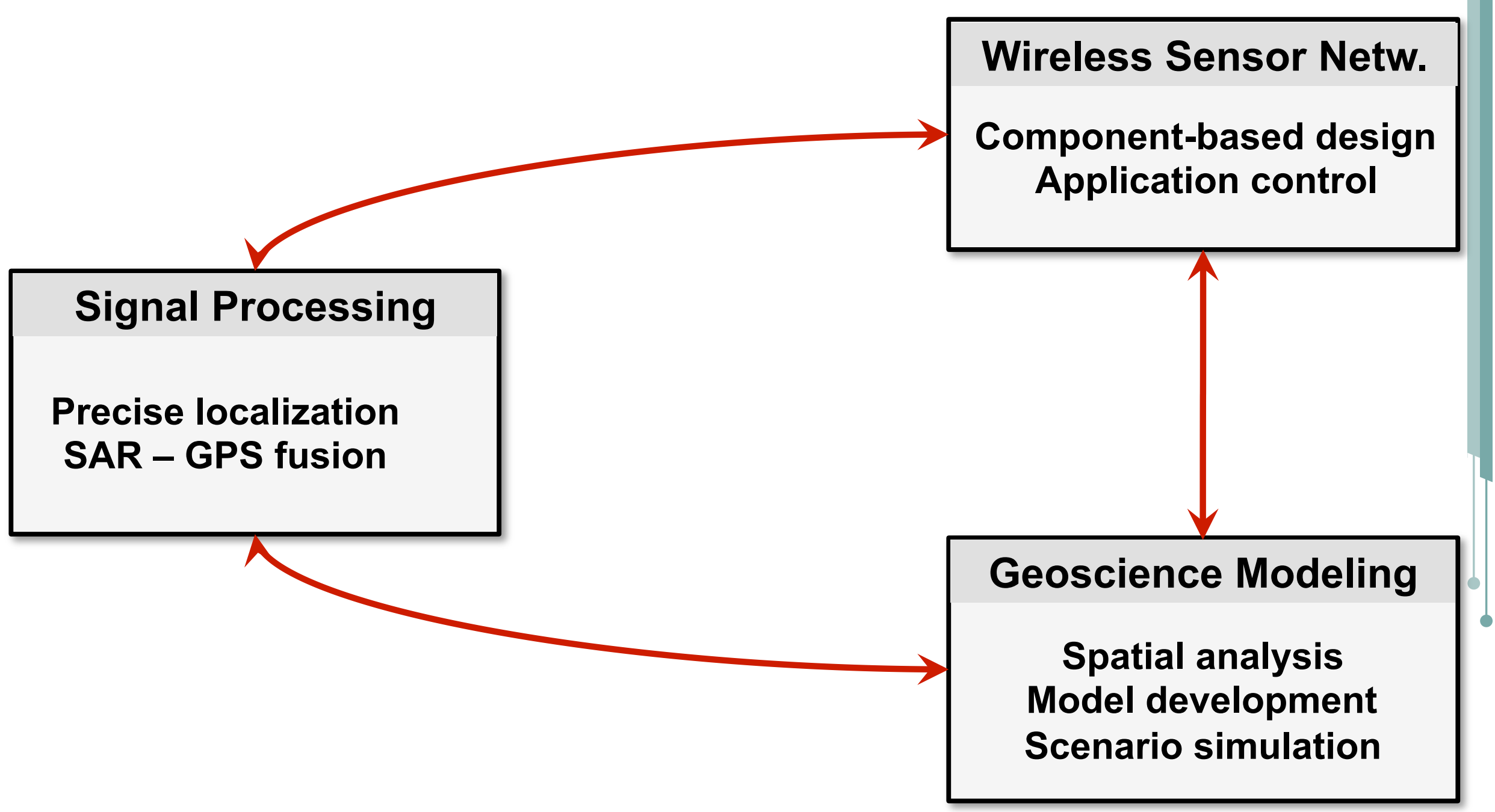




\section{Challenge: the physical environment}

- Lightning, avalanches, rime, prolonged snow/ice cover, rockfall

- Strong daily variation of temperature

- -30 to $+40^{\circ} \mathrm{C}$

- $\Delta \mathrm{T} \leqq 20^{\circ} \mathrm{C} / \mathrm{hour}$
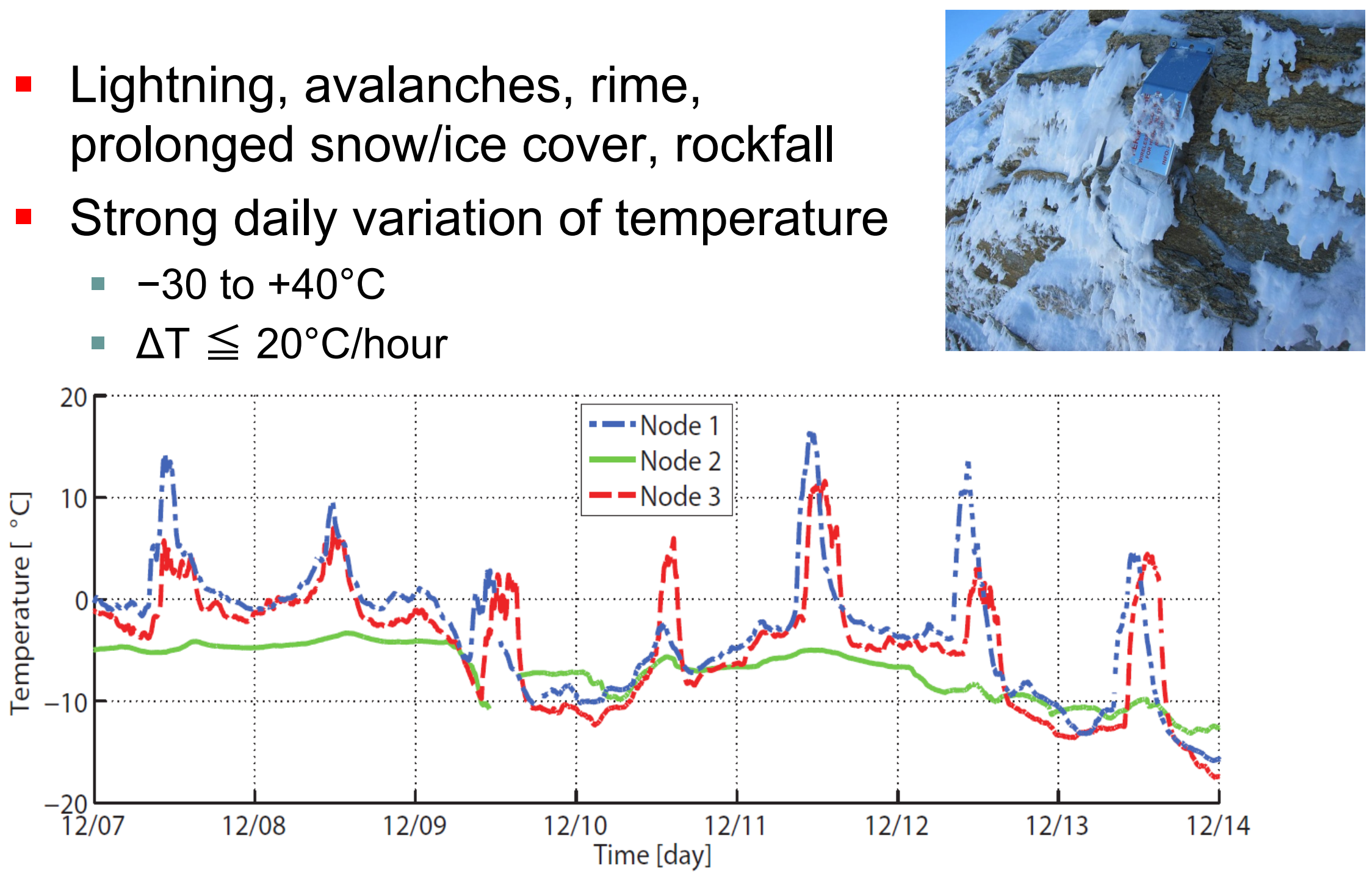

(c) Giovanni De Micheli -- ASPDAC 2012 


\section{In situ design and test}

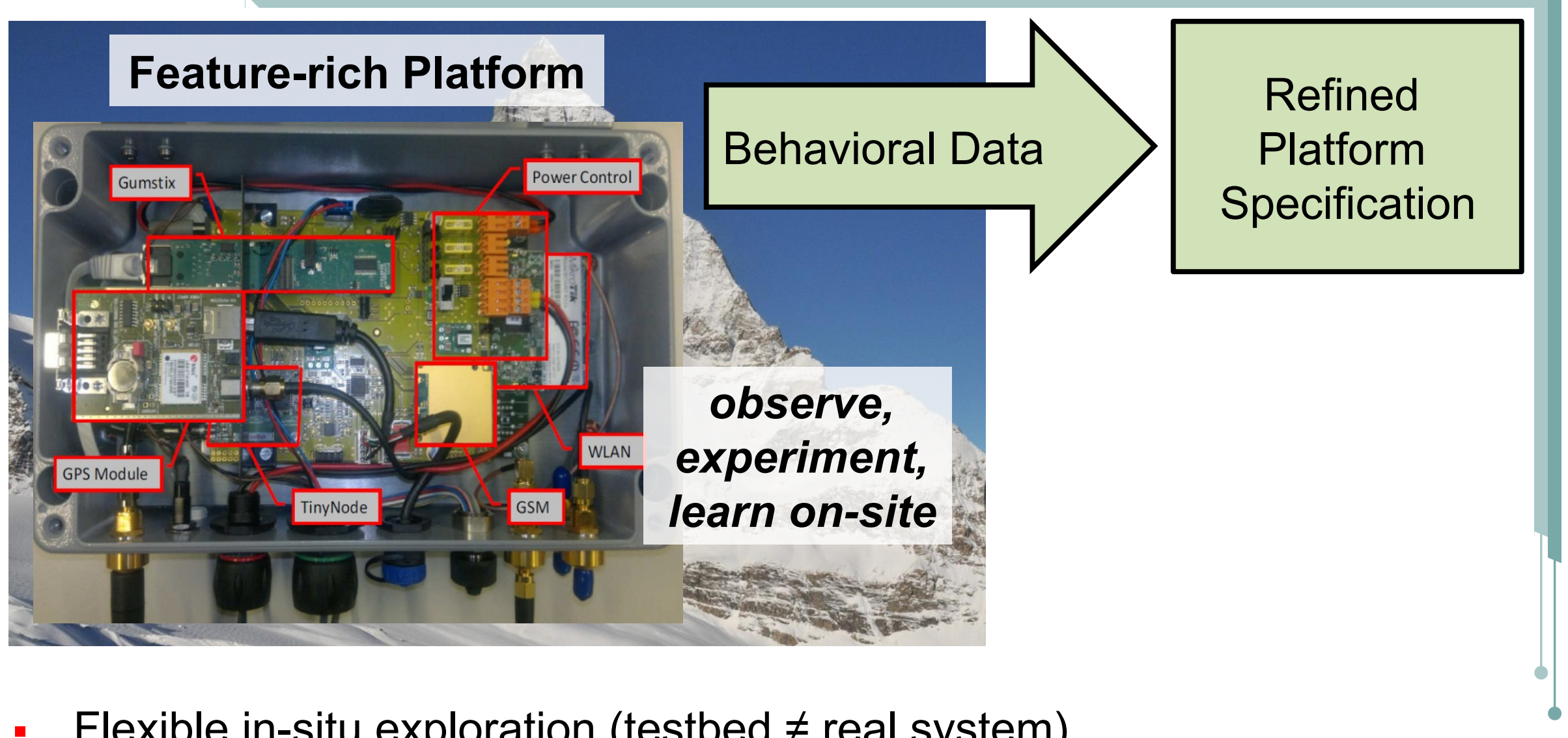

- Flexible in-situ exploration (testbed $\neq$ real system)

- Real sensor data, real environment

- Integration with live data management (system of systems) 


\section{GPS measurement devices}

\section{Low-cost GPS Devices}

- Dual strategy: logging units \& wireless sensors

- High temporal resolution

- Accurate displacement-rate of a boulder (mm-cm accuracy for daily position)
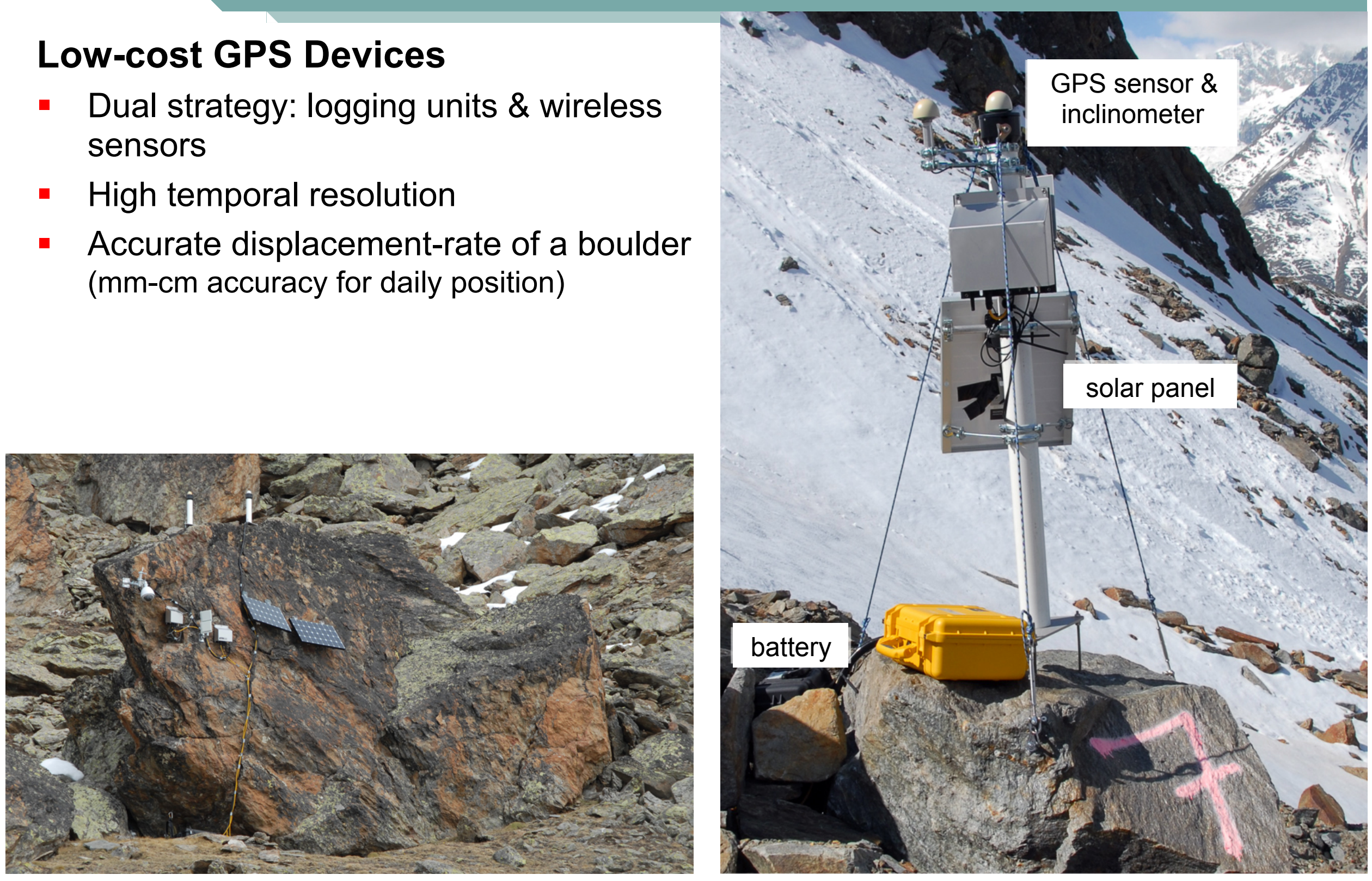


\section{GPS deployment: Matter valley}

\section{Field Site Inventory}

- 9 GPS on composite landslides

- 8 GPS on rock glaciers

- 4 GPS as position reference stations

- 5 simple temperature loggers per GPS station

- 2 Meteo stations

- 1 camera

Installation started August 2010, with full operability in August 2011

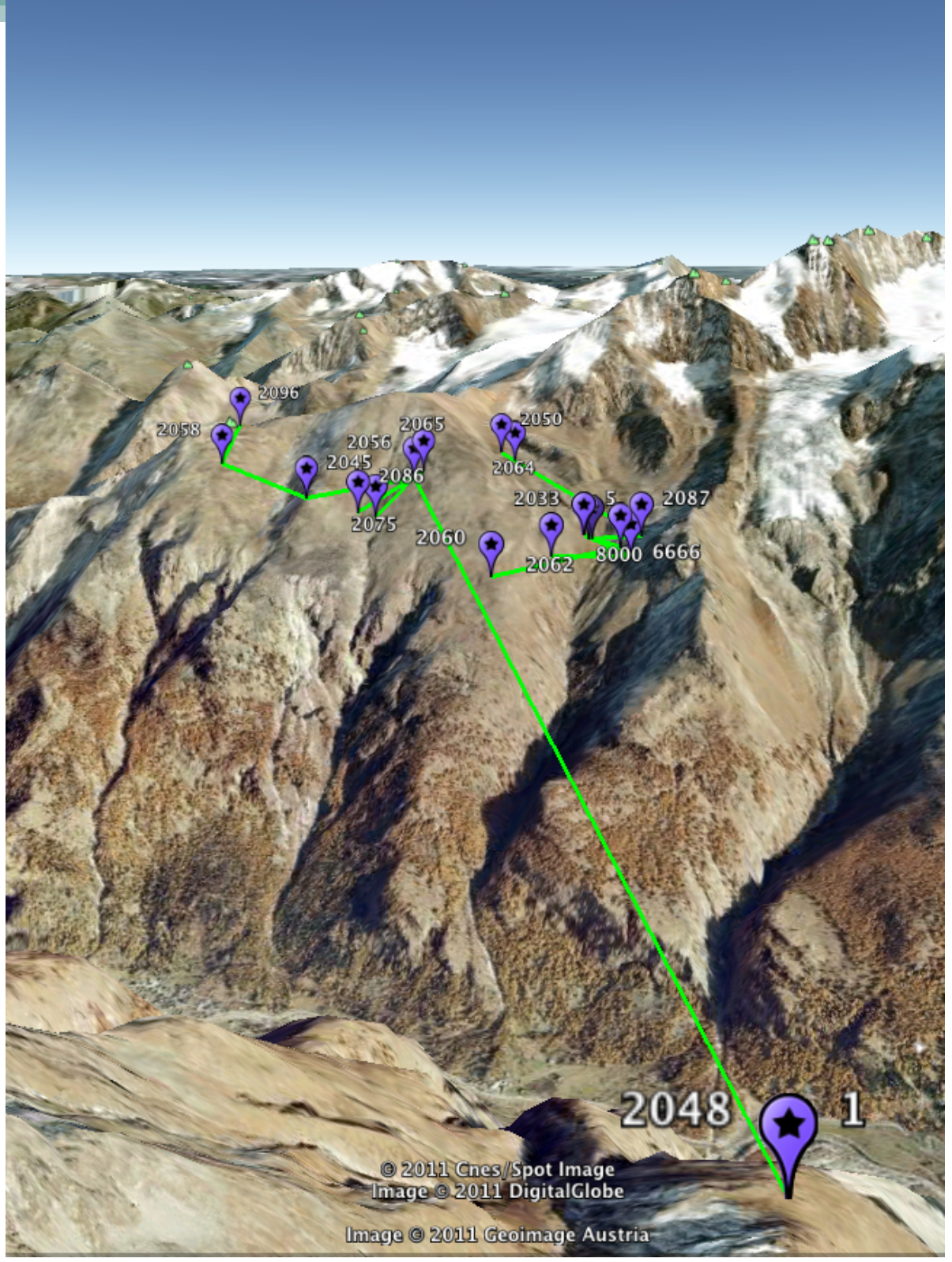




\section{X-sense: scientific challenges}

- Design, deploy, test sensor nodes

- Rugged electronics

- Highly-reliable units

- Gather, fuse data from various sources

- Algorithms and software for data processing

- Map data onto to geological model

- Correlate physical measurements

- Extract potential alarming situation 


\section{Enabling technologies and platforms}

- Enabling technologies as common research areas to support health and environment application

- Micro/nano-electronics

- Sensors

- MEMS/NEMS

- Information and communication systems

- Design platforms

- Low power sensing, processing and communication

- 3-Dimensional integration and packaging

- Body-area and ad hoc networks
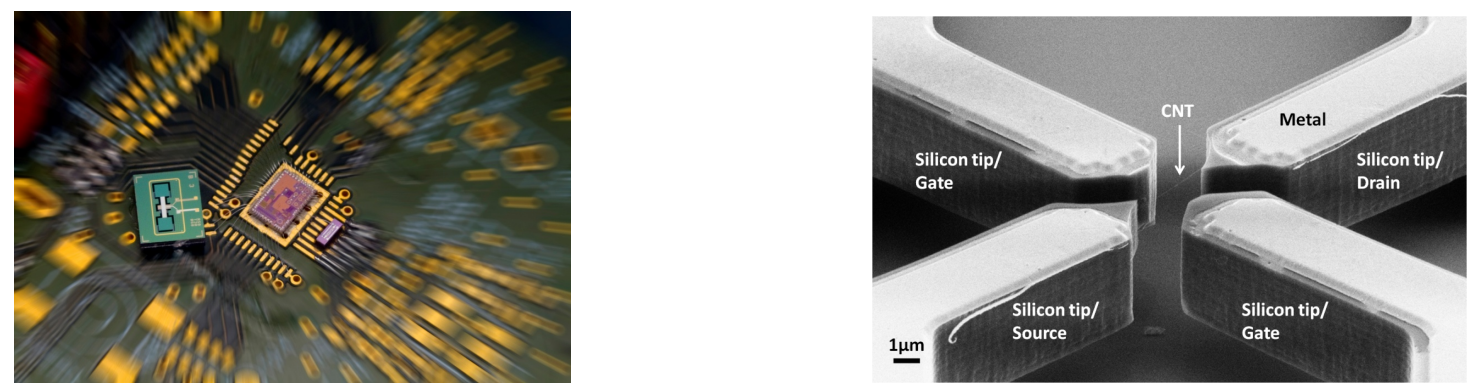


\section{Conclusions}

- Nano-Tera.ch exploits new technologies and devices:

- Silicon nanowire and carbon nanotube devices

- Integrated electronics and sensors

- With the objective of building heterogeneous systems:

- Monitor health in patients, disabled and elderly

- Monitor the environment for pollution and to prevent disasters

- And with the final goal of increasing the security of individuals and communities

- Key contribution of engineering to coping with complex societal and economic problems

- Requiring large and collaborative intellectual effort 


\section{Thank you}

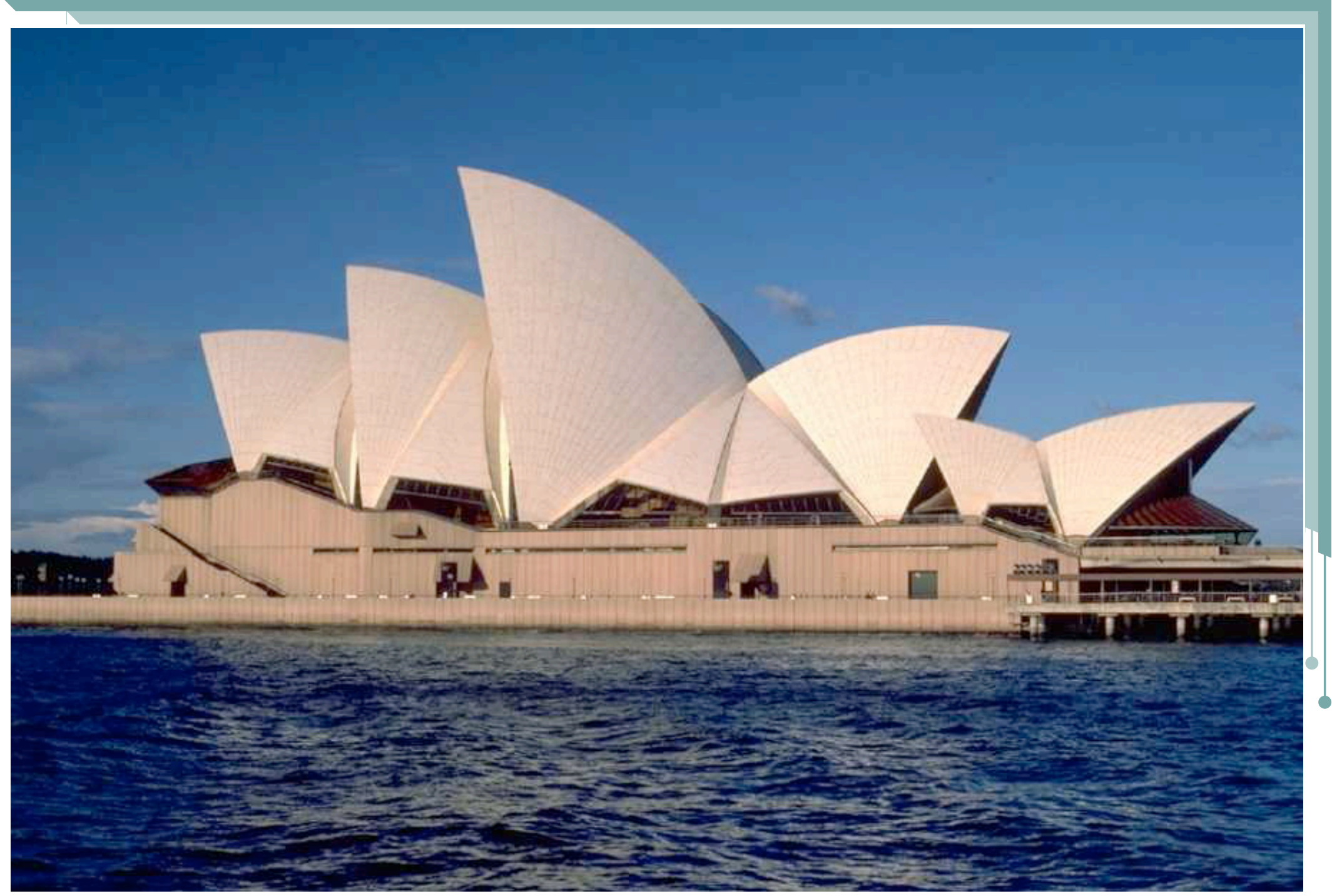

